\title{
On the causes and effects of inhibition of return
}

\author{
TRACY L. TAYLOR and RAYMOND M. KLEIN \\ Dalhousie University, Halifax, Nova Scotia, Canada
}

\begin{abstract}
Unpredictive visual transient cues have a biphasic effect on reaction times (RTs) to peripheral onset targets. At relatively short (e.g., 150-msec) cue-target stimulus onset asynchronies (SOAs), RTs to targets at cued versus uncued locations are facilitated, whereas at relatively long SOAs (e.g., beyond $300 \mathrm{msec}$ ), they are inhibited. The present review explores the conditions under which this latter, inhibitory, effect - referred to as inhibition of return (IOR; Posner \& Cohen, 1984) - is revealed and those conditions under which it is generated. We argue that the extant literature converges on the view that IOR reflects a motor response bias that is generated by the activation of an oculomotor program to fixate the cue. However, we reveal that current conceptualizations of IOR are based on a limited sampling of possible tests of the generation and measurement of IOR and indicate where further experimental research is critical.
\end{abstract}

Using a variant of a spatial orienting paradigm (cf. Posner, 1980), Posner and Cohen (1984) observed that peripheral luminance changes have a biphasic effect on manual reaction times (RTs) to detect subsequent luminance onset targets. Posner and Cohen (1984) presented subjects with three horizontally aligned outline boxes. At the beginning of a trial, one of the peripheral boxes was cued via a brief brightening. This cue was unpredictive of target location. Indeed, regardless of the location of the peripheral brightening, targets appeared with $60 \%$ probability in the fixated center location, with $10 \%$ probability at each of the two peripheral locations, and were withheld with $20 \%$ probability (catch trials).

Combined with eye movement monitoring, these predetermined spatial probabilities encouraged subjects to maintain both their eyes and their attention at center. Despite incentive to focus attention at the fixated location, however, RTs to peripheral targets were impacted in accordance with their spatiat and temporal contiguity with the cue. In particular, at short (i.e., less than approximately 150-msec) cue-target stimulus onset asynchronies (SOAs), RTs were facilitated to targets that appeared at the same location as the cue; at long (i.e., in excess of approximately $300-\mathrm{msec}$ ) cue-target SOAs, this trend reversed, and RTs were inhibited to targets that appeared at the same location as the cue. ${ }^{1}$

This work derives from a dissertation submitted in partial fulfillment of the PhD degree at Dalhousie University and was supported by Natural Sciences and Engineering Research Council of Canada (NSERC) and Killam Memorial Trust Fund scholarships to the first author and by NSERC grants held by the second author. We thank Patricia McMullen, Bruce Earhard, Thomas Carr, and Chris Moore for their feedback on earlier versions of this work. We thank Richard Schweikert, Brad Gibson, and two anonymous reviewers for the time and care they put into reviewing our paper and for their stimulating comments on our work. Please address reprint requests to T. L. Taylor, Department of Psychology, Wilson Hall, Vanderbilt University, Nashville, TN 32740 (e-mail: tracy.l.taylor@vanderbilt.edu).
The facilitatory component of the observed biphasic effect of a visual transient cue is due to covert orienting of visuospatial attention. As distinguished from overt orienting - which refers to the alignment of peripheral visual receptors with the source of visual input (e.g., through saccadic eye movements) - covert orienting refers to the allocation of attentional resources to a spatial location or object independently of changes in gaze direction. Such covert orienting can be accomplished by the operation of two distinct but interacting control systems (see, e.g., Briand \& Klein, 1987; Klein, 1994; Klein \& Hansen, 1990; Klein, Kingstone, \& Pontefract, 1992, for a review; Theeuwes, 1991; in contrast with Jonides, 1980 , 1981, and Müller \& Rabbitt, 1989). One of these systems is endogenous; the other is exogenous. Endogenous covert orienting is accomplished via task demands, stimulus probabilities, or symbolic cues that encourage top-down allocation of attentional resources to a location (see Posner, 1980), to an object (Duncan, 1984), or to the development of a nonspatial expectancy (see Kingstone \& Klein, 1991; Klein \& Hansen, 1990; Lambert \& Hockey, 1986). Exogenous covert orienting, on the other hand, is achieved automatically, via bottom-up activation of transient visual channels that code the location of an abrupt luminance change (see Nakayama \& Mackeben, 1989).

Whether allocated endogenously or exogenously, the locus of attention can be inferred through chronometric analysis of performance. With respect to spatial orienting, this analysis presumes that attention has been oriented in accordance with a cue when performance (e.g., RT) is relatively improved (benefits) for responses to targets that appear at a cued location and relatively impaired (costs) for responses to targets that appear at an uncued location (see Posner, 1980). ${ }^{2}$

Given this distinction between endogenous and exogenous control, the RT facilitation observed by Posner and Cohen (1984) at early cue-target SOAs reflects exogenous capture of attention by the visual transient cue. That this early facilitation is replaced by a later inhibition has been 
said to depend on the withdrawal of attention back to fixation following initial exogenous capture by the peripheral cue (however, see Berger, 1992, as cited in Rafal \& Henik, 1994; and for demonstrations of inhibition of return [IOR] at fixation, see Maylor \& Hockey, 1985; Possamai, 1986). In Posner and Cohen's (1984) original study, such withdrawal back to fixation was encouraged by the high probability of target occurrence at that location. However, subsequent studies have found a similar biphasic effect of luminance cues even when target probabilities are equated across location. These studies rely on subjects' endogenous motivation to maintain attention centrally in the absence of incentive to allocate resources elsewhere (see Possamai, 1986) and/or interpose a centrally presented luminance transient in order to exogenously summon the return of attention to fixation (see Posner \& Cohen, 1984).

Regardless of whether attention is drawn back to center endogenously via task demands and/or exogenously via a luminance change at fixation, inhibitory aftereffects of the prior cue are observed at relatively long cue-target intervals. This finding of an inhibitory aftereffect following the withdrawal of attention from a peripheral location, however, occurs only when the initial orienting is accomplished without exclusively endogenous control: When Posner and Cohen (1984) attempted to replicate their pattern of biphasic results using a spatially predictive endogenous cue, they failed to find the signature crossover interaction of SOA and cue-target spatial congruity.

In this attempted replication, Posner and Cohen (1984) presented subjects with a directional arrow at fixation (see also Rafal, Calabresi, Brennan, \& Sciolto, 1989). On half of the trials, the arrow cue was followed at a relatively long interval by a target whose location was predicted with $80 \%$ validity by the direction indicated by the cue. On the other half of the trials, the center box brightened in order to summon attention exogenously, and target probabilities were reestablished with $60 \%$ probability at center and $20 \%$ at each of the two peripheral locations (thereby canceling the predictive validity of the cue). There was no evidence of inhibitory consequences.

Taking into account the conditions under which an inhibitory effect is observed, Posner, Rafal, Choate, and Vaughan (1985) coined the term inhibition of return to refer to this inhibitory component of the biphasic pattern. This terminology derives from the belief that attention is drawn reflexively to the location of the luminance cue and that, following the withdrawal of attention back to fixation, attention is then relatively impaired for returning to the previously cued location. In other words, Posner et al. (1985) characterized IOR as an effect of attention on attention.

Two things are important about this definition of IOR. The first is that it makes a distinction between what is measured by IOR (impaired attentional orienting) and how that inhibition is generated (initial attentional orient- ing to the exogenous cue). The second is that, by characterizing IOR as inhibited attentional orienting owing to initial exogenous attentional orienting, Posner et al. (1985) stimulated considerable research into the nature and source of IOR. By utilizing the distinction between what is measured by IOR and how the inhibition is generated, the following review will examine these investigations. We will first consider the issue of what is inhibited by IOR. In this regard, we will explore the possibility that IOR (1) occurs at the level of sensory registration, (2) reflects a deficit for perceptual processing owing to inhibited attentional orienting, and (3) is a motor response bias. We will then consider the issue of how IOR is generated. In this regard, we will consider whether IOR may result from (1) inhibition of an overt response to the peripheral cue, (2) exogenous attentional orienting to the peripheral cue, or (3) activation of an oculomotor program to fixate the cued location. On the basis of our analysis of the literature, we argue that IOR is perhaps best characterized as motor response bias that is generated by oculomotor programming. Where possible, we will consider plausible neural substrates for this presumed motor basis of IOR.

What will become clear in arriving at a conceptualization of IOR as a motor effect is that this view is favored by default rather than by design. In other words, alternative conceptualizations of IOR have met with contradictions to their predictions, whereas the motor view gains strength from never having been tested directly (or, therefore, contradicted). Although the accumulation of positive evidence is suggestive, it is, of course, necessary to test directly the predictions of a motor view of IOR before accepting it as a mechanism for IOR (see Taylor, 1997; Taylor \& Klein, 1998b). As such, we will conclude our review by identifying key experiments that would test predictions made by the view that IOR is a motor response bias that results from prior oculomotor programming.

\section{INHIBITION OF RETURN: WHAT IS INHIBITED?}

Since the discovery of IOR, several different views of what is inhibited have been proposed. According to one account, IOR is akin to sensory masking or habituation, wherein stimulation provided by the cue interferes with subsequent target processing by the sensory receptors (see, e.g., Posner \& Cohen, 1984). However, this explanation seems unlikely. First, IOR occurs at cue-target SOAs outside the typical range for masking effects (see, e.g., Foley \& Boynton, 1993). Second, IOR is a longer lasting effect than sensory masking (lasting up to $1.5 \mathrm{sec}$; Berlucchi, Tassinari, Marzi, \& DiStefano, 1989). And third, if sensory processes were inhibited because of cue presentation, target detection might be expected to suffer at early as well as late SOAs. With respect to this latter point, the fact of early facilitation of target detection is inconsistent with a sensory masking or habituation 
effect - unless it is assumed that the early facilitation is due to spatial and/or temporal summation of cue and target luminance.

Noting that Posner and Cohen (1984) obtained facilitation only for SOAs at which target occurrence overlapped with or else was in close temporal proximity to cue presentation, Tassinari, Aglioti, Chelazzi, Peru, and Berlucchi (1994) manipulated systematically the temporal relation between cue and target (see also Possamai, 1986). In different experiments, they (1) presented cues and targets of short (16-msec) duration; (2) presented cues that, regardless of SOA, outlasted the $16-\mathrm{msec}$ target by a fixed duration of $300 \mathrm{msec}$; and (3) replicated Posner and Cohen's (1984) 150-msec cue duration in combination with a $16-\mathrm{msec}$ target presentation. In all cases, the biphasic pattern of results was obtained as a function of cue-target SOA, thereby indicating that it is likely that the early facilitatory effect does not depend on luminance summation of cue and target. This conclusion is bolstered by noting that a biphasic pattern of results is also obtained with peripheral cues that dim rather than brighten (Posner \& Cohen, 1984).

Of course, even without local summation of cue/target luminance at early SOAs, it could be argued that IOR reflects a sensory processing deficit and that the failure to observe this deficit at early SOAs is due to a different time course for facilitatory and inhibitory effects of the cue. In other words, the cue may result in a sensory deficit that is masked at early SOAs by facilitatory processes (e.g., improved perceptual processing, owing to the allocation of covert attention). Contrary to a low-level visuosensory account of IOR effects, however, there are three lines of evidence that negate local cue--target interactions at the retina. These lines of evidence, outlined below, are corroborated to the extent that a unitary effect is represented by the observation of inhibition for ipsilateral cues and targets within and across visual, auditory, and somatosensory modalities (Breau, Mondor, \& Milliken, 1995; Reuter-Lorenz, Jha, \& Rosenquist, 1996; Schmidt, 1996b; Spence \& Driver, 1998a, 1998b; Tassinari \& Berlucchi, 1995; Tassinari \& Campara, 1996). If evidence should bear out the supposition that visual, auditory, and somatosensory inhibitory effects stem from the same, supramodal, mechanism (see Ward, 1994), this would obviously present conclusive evidence against retinal interactions.

The possibility of a supramodal mechanism notwithstanding, there are data within the visual domain that argue against IOR at the level of the retina. The first line of evidence stems from the observation that IOR shows interocular transfer. Employing a dichoptic-viewing methodology, Tassinari and Berlucchi (1993) required subjects to view stimuli through goggles that had a red filter over one eye and a green filter over the other. Cues and targets were red or green and, on a trial, did not share the same color. As such, the goggles filtered the cue to one eye and the target to the other. In spite of the fact that cues and targets were not processed by the same retina, IOR was observed (see also Maylor, 1983, as cited in
Maylor \& Hockey, 1985). Moreover, when compared to equivalent conditions run under binocular viewing, the magnitude of the IOR effect was not reduced by the dichoptic-viewing procedures $(M=37 \mathrm{msec}$ under binocular viewing and $48 \mathrm{msec}$ under dichoptic viewing; see Tassinari \& Berlucchi, 1993, same point RT-opposite point RT in their Tables 1 and 2).

The second line of evidence arguing against slowed retinal processing is that IOR occurs at locations remote from the cue. Maylor and Hockey (1985) presented subjects with a cue $12^{\circ}$ visual angle to the direct left or right of fixation. This cue was followed after a variable SOA by a target that could occur in any 1 of 14 positions: Seven positions were on either side of fixation, with 3 above and 3 below the center location (that could also serve as cue); the vertical extent of possible target locations was $4.5^{\circ}$ visual angle above and below the horizontal meridian. IOR was distributed in a graded but nonlinear fashion according to the vertical distance between cue and target within a hemifield (for evidence that the inhibitory gradients do not cross the horizontal or vertical meridia, see Berlucchi et al., 1989; Tassinari, Aglioti, Chelazzi, Marzi, \& Berlucchi, 1987).

Finally, the third line of evidence against retinal cuetarget interactions stems from the demonstration that IOR is not coded in retinotopic coordinates. Maylor and Hockey (1985) presented subjects with two fixation crosses-one directly below the other. Subjects began with their eyes on the upper fixation stimulus, and a cue was presented at the target locations to the upper left or upper right of this original fixation location. When the cue was extinguished, subjects saccaded to and then maintained fixation on the lower fixation stimulus. Relative to this second fixation, a target requiring a manual detection response appeared with equal probability at one of four locations. Two of these locations were the original locations that had been cued (i.e., they occupied the same environmental but not the same retinal coordinates as the cue), and two of these locations shared the same spatial relation relative to the second fixation stimulus as the possible cued locations shared relative to the first fixation stimulus (i.e., they occupied the same retinal but not the same environmental coordinates as the cue). The results indicated that it is the cued environmental location that suffers the repercussions of IOR and not the cued retinal location (see also Posner \& Cohen, 1984). Moreover, when an object is presented at a cued environmental location and then moves from that position, IOR follows the object-even if the object rotates in a $180^{\circ}$ arc around fixation in order to occupy the mirror-symmetric location (Tipper, Driver, \& Weaver, 1991; Tipper, Weaver, Jerreat, \& Burak, 1994; however, see Müller \& von Mühlenen, 1996, and Weaver, Lupiáñez, \& Watson's, 1998, response). Such environmental coding of locations or objects is antithetic to a retinal basis of IOR.

If IOR is not inhibition of low-level sensory registration of target information at the cued location, then what is inhibited as a result of prior cue presentation? Two al- 
ternatives are predominant in the literature. The first follows from Posner et al.'s (1985) functional interpretation of IOR and posits that it is covert attention that is inhibited from returning to the previously cued location. As will be seen, the second follows from repeated demonstrations that IOR occurs only under limited conditions in paradigms that are known to be sensitive to the effects of attentional processing. Championed by Klein and Taylor (1994), this second view posits that IOR is a motor bias against making responses to a target that has appeared in a previously cued location (see also, e.g., Posner \& Cohen, 1984; Rafal et al., 1989, for arguments supporting an oculomotor basis of the effect).

The view that IOR represents inhibition for returning attention to a previously cued location implies a reduction in the speed and/or efficiency of perceptual processing at that location. ${ }^{3}$ In this case, perceptual inhibition is distinguished from postulated sensory inhibition, on the grounds that it is the speed or accuracy with which the percept is formed from the sensory registry that is affected, not the sensory registration itself. That attention affects the efficiency to process stimuli that occur at (or near) the cued location is well established (Bushnell, Goldberg, \& Robinson, 1981; Corbetta, Miezin, Dobmeyer, Shulman, \& Petersen, 1990; Downing, 1988; Hawkins et al., 1990; Hawkins, Shafto, \& Richardson, 1988; Lyon, 1990; Mangun, Hansen, \& Hillyard, 1986; Mangun \& Hillyard, 1991; Müller \& Findlay, 1987; however, see Shiu \& Pashler, 1994, 1995). It follows that, if IOR is inhibition for returning attention to a previously cued location, it should be influenced similarly by factors that affect the magnitude of attentional costs and benefits and should be reflected in the performance of perceptually based tasks that are sensitive to attentional allocation. As the following will reveal, the evidence on this matter is mixed but does tend to favor a motor account.

Reuter-Lorenz et al. (1996) noted that the magnitude of attentional costs and benefits is greater for visual than for auditory targets, greater for low intensity than for high intensity targets, and equivalent for manual detection and saccadic responses. As such, they argued that, to the extent that IOR and attentional orienting share a common mechanism, the magnitude of IOR should be similarly influenced by target modality, target intensity, and response mode. To test this hypothesis, Reuter-Lorenz et al. (1996) presented subjects with a brightening to the left or the right, a brightening at fixation, and a visual or auditory target to the left or the right. The results were consistent with patterns of attentional orienting effects. Specifically, the magnitude of IOR was greater for visual than for auditory targets, greater for low intensity than for high intensity targets, and equivalent for manual detection and saccadic responses.

Whereas Reuter-Lorenz et al.'s (1996) results are consistent with there being a commonality between attentional orienting and IOR, studies that have assessed the impact of IOR on the speed and quality of perceptual processing have generally converged on the conclusion that
IOR is not attentional. More particularly, within the context of temporal order judgments and the frequency of illusory line motion studies, there is no evidence to suggest that IOR reflects slowed perceptual processing (or, by implication, slowed attentional orienting). And, when studied in the context of target manipulations that require nonspatial discrimination responses, IOR fails to consistently impact the quality of forming perceptual representations of stimuli appearing at the previously cued location.

Temporal order judgments are used to assess the locus of covert attention and are predicated on the perception of prior entry (i.e., early perceptual awareness of a stimulus) because of speeded transmission of stimuli at an attended location (see Hikosaka, Miyauchi, \& Shimojo, 1993a; Stelmach \& Herdman, 1991; Sternberg \& Knoll, 1973). In a temporal order judgment task, two stimuli are presented, with a variable delay imposed between the onset of one and the onset of the other; both remain visible throughout the trial duration, and the subject's task is to indicate which was onset first. The notion of prior entry maintains that, if stimuli are presented simultaneously (i.e., with a 0 -msec delay) —one at a cued location and one at an uncued location-subjects are likely to report the stimulus at the cued location as preceding that at the uncued location. This is depicted in Figure 1 where, at a short SOA, simultaneously onset targets are perceived as though the target in the cued location was onset before the target in the uncued location. Using the same reasoning, if there is a (nonzero) delay between the onsets of the two stimuli, attention serves to (1) lengthen the perceived delay when the leading stimulus is at the cued location, and (2) shorten the perceived delay when the leading stimulus is at the unattended location, affecting the judgment of the leading stimulus accordingly.

If IOR is inhibition for returning attention to a previously cued location, temporal order judgments should be impacted in the manner outlined in Figure 1 for long SOAs. In particular, if IOR represents inhibited return of attention to the previously cued location, at long cue-target SOAs transmission from the cued location should be slowed relative to the uncued location. In the simplest example of two stimuli being onset simultaneously (as is depicted in Figure 1), subjects should perceive the stimulus from the uncued location as being onset first; when a delay separates the onsets of the two stimuli, there should be longer perceived delays (hence, greater accuracy of temporal order judgment) when the stimulus in the uncued location leads and shorter perceived delays (hence, lower accuracy of temporal order judgment) when the stimulus at the cued location leads. This does not occur. When accuracy is the dependent variable in a temporal order judgment task, subjects show no evidence of slowed transmission from the cued location (Maylor, 1985; Posner et al., 1985).

The frequency of illusory line motion is similarly predicated on the notion of prior entry (see e.g., Hikosaka, Miyauchi, \& Shimojo, 1993a, 1993b, 1993c; however, 


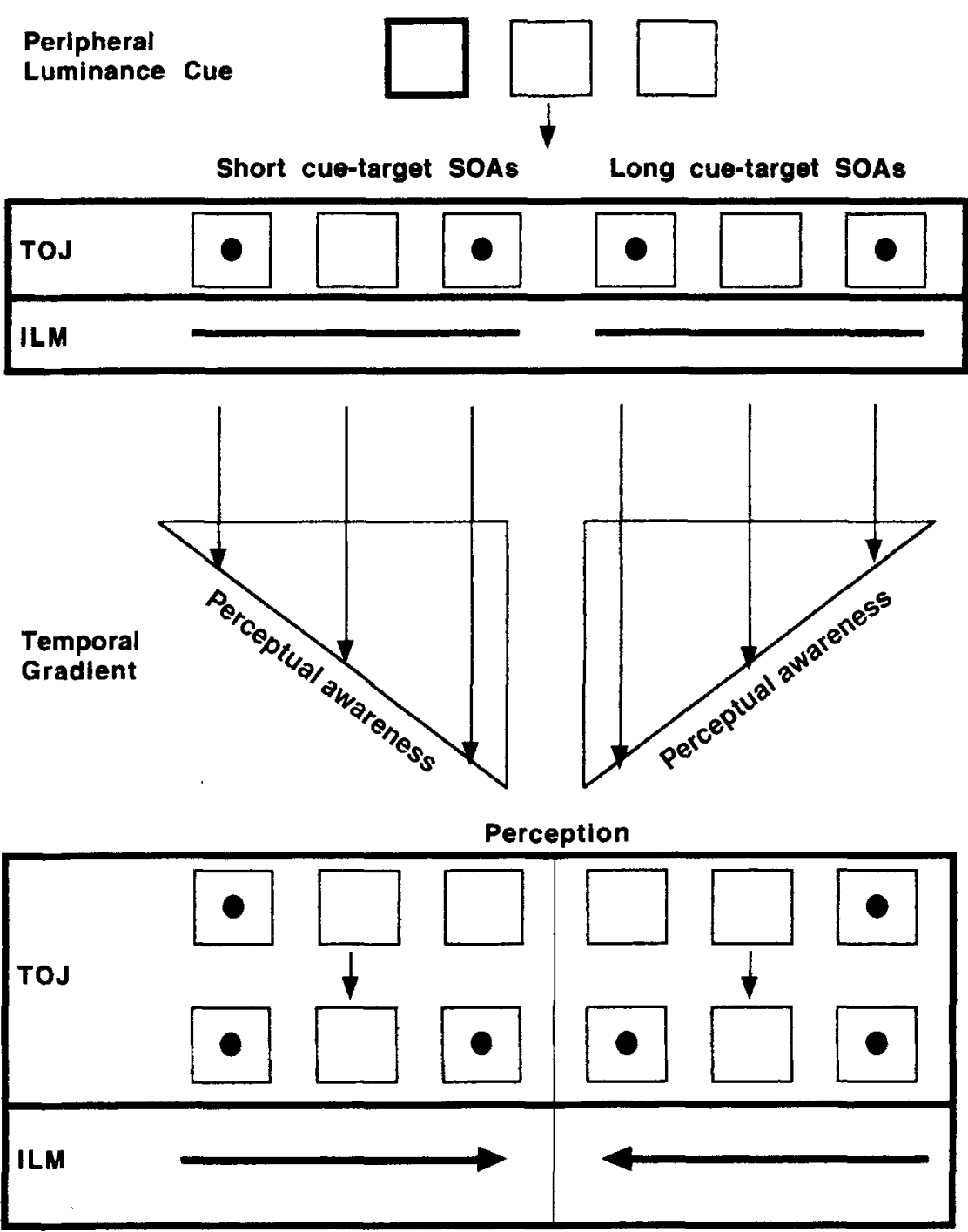

Figure 1. Hypothesized perception of simultaneously onset targets in a temporal order judgment (TOJ) paradigm and of an onset line in a frequency of illusory line motion (ILM) paradigm. According to the notion of prior entry, attention serves to speed (in a graded fashion) the transmission of visual signals that arise at or near the attended location. As such, to the extent that attention is captured by an initial onset cue, at short SOAs, stimuli occurring near the cued location should reach perceptual awareness sooner than stimuli occurring further away from the cued location. In this example of an initial cue to the left, at short SOAs, the simultaneously onset targets in a TOJ paradigm should be perceived as though the left target occurred before the right target; the onset line in the ILM paradigm should be perceived as though it had been drawn from left to right. By the same principle, to the extent that IOR reflects inhibited attentional orienting to the previously cued location, at long SOAs, this gradient should reverse, so that signals arising from the inhibited location are now processed more slowly than signals arising from locations further away. In this example of an initial cue to the left, the prediction is that, at long SOAs, simultaneously onset targets in a TOJ paradigm should be perceived as though the right target was onset before the left; an onset line in the ILM paradigm should be perceived as though it was drawn from the right to the left.

see C. J. Downing \& Treisman. 1995; P. E. Downing \& Treisman, 1997). Unlike a temporal order judgment task, however, which typically involves an actual temporal delay between the onsets of events at disparate locations. the assessment of illusory line motion is made by presenting a line all at once and having subjects judge whether it appears to show motion. In this regard, it is similar, in principle, to the case in which a temporal order judgment is made to simultaneously onset stimuli. To the extent that attention speeds the transmission of neural signals, an illusion of motion away from an attended location would be predicted to result from the fact that the 
end of the line near the locus of attention is perceived sooner than parts of the line that are more distant from that locus.

The rationale for determining whether the frequency of illusory line motion supports a perceptual basis of IOR is similar to the rationale underlying the attempt to find IOR with a temporal order judgment. Consider the example depicted in Figure 1. A cue is presented to the left of fixation and followed at variable SOAs by a line that joins the cued and uncued locations. Using this procedure, Schmidt (1996a) reasoned that, if IOR is inhibition of perceptual processing, at short cue-target SOAs an illusion of motion away from the cued location should predominate, whereas at long cue-target SOAs an illusion of motion away from the uncued location should predominate. Despite being able to demonstrate the efficacy of his cuing procedures for inducing IOR in a manual detection task, Schmidt (1996a) found no evidence for inhibited perceptual processing at the cued location at any of the SOAs tested.

Results from the temporal order judgment and frequency of illusory line motion tasks contradict the postulate that IOR is inhibition for the speed of perceptual processing. Nevertheless, an attentional explanation of IOR can be rescued if it is assumed that the quality of a perceptual representation might be inhibited independently of the speed of forming that representation. In other words, even if IOR does not reflect slowed transmission of sensory signals from a previously cued location, if perceptual awareness of the sensory activation is an insufficient basis on which to generate the response, IOR might be observed because of a poor-quality percept from that location. Results from nonspatial discrimination tasks, however, demonstrate that this is not generally the case (see below for exceptions). When a target is presented at a previously cued location, IOR is not observed for discriminations of Vernier offset (Tanaka \& Shimojo, 1996), size change (Pontefract \& Klein, 1988), luminance (Tanaka \& Shimojo, 1996), color (Tanaka \& Shimojo, 1996; however, see Law, Pratt, \& Abrams, 1995, and Taylor \& Klein's, 1998a, challenge to them), orientation (Tanaka \& Shimojo, 1996), or form (Terry, Valdes, \& Neill, 1994).

The failure to consistently observe IOR for target discriminations is not due to the choice response per se. It is well established that IOR can be obtained for choice responses based on target localization and does not depend on simple manual detection. For instance, IOR is obtained for (1) lateralized saccadic eye movements made to the target location (Abrams \& Dobkin, 1994, 1995; Maylor, 1985; Posner \& Cohen, 1984; Rafal, Egly, \& Rhodes, 1994; Reuter-Lorenz, et al., 1996; Vaughan, 1984), (2) manual localization responses (i.e., left-right; see, e.g., Maylor, 1985; Tanaka \& Shimojo, 1996), and (3) nonspatial target discrimination tasks that require a localization response (e.g., saccade to a target square and away from a distractor diamond; Pratt, 1995).
This dissociation between nonspatial discrimination tasks and those based on target localization corresponds with the neurophysiological distinction between the ventral ("what") and dorsal ("where") pathways, as noted by Tanaka and Shimojo (1996). At a gross level, the ventral pathway leads to object recognition via the analysis of information through to the inferotemporal cortex; the dorsal pathway leads to object localization via the analysis of information through to the parietal cortex, via the superior colliculus (SC). The fact that IOR occurs for localization but not for nonspatial target discriminations therefore suggests that IOR might be mediated by the dorsal pathway. ${ }^{4}$ Because the analysis of stimulus location guides directed motor responses, inhibition of activity associated with the dorsal representation of a spatial location would predict slower responses to that location.

This view of dorsal pathway involvement offers a possible neural correlate for Klein and Taylor's (1994) view of what is inhibited by IOR. In particular, Klein and Taylor noted the preponderance of evidence showing that IOR occurs only for target localization and, on these grounds, argued that IOR is not inhibition of attention but, rather, is inhibition for making motor responses to a previously cued location. They posited that IOR is represented in a spatial motor map that directs action: "In essence, there is a criterion shift for responding that something has happened at a particular location ... this shift does not affect the processing efficiency of information coming from the attended location ... the criterion is changed for 'responses to' stimuli from a particular location" (Klein \& Taylor, p. 143). In addition to accounting for data already presented, this motor biasing account of IOR is able to predict the additional finding that IOR not only slows saccadic latencies but also biases saccade direction.

Consider that, if IOR is a motor bias against responding to targets arising at the previously cued location, this criterion change for responding in the cued direction should be reflected in a response measure based on directional preference. Using a temporal-order-judgmenttype task, Posner et al. (1985) presented subjects with a luminance increment cue at one of two peripheral locations. This cue was followed by a brightening at fixation. Then, after a relatively long SOA, a lead target dot appeared at one of the two peripheral locations, followed $10,25,45$, or $200 \mathrm{msec}$ later by the onset of a second target dot in the other peripheral location. Subjects were instructed to move their eyes in the "most comfortable" direction following target onset.

The cue-(lead) target SOAs were within the range for obtaining IOR. As such, the dependent variable of interest was whether subjects would tend to demonstrate a motor bias by moving their eyes away from the previously cued location - at least when the interval separating the onset of the two targets was short. On the majority of trials, subjects tended to move their eyes in the direction of the target that actually led; however, at the three shortest 
target-target intervals, this tendency was offset by a bias to move the eyes away from the cued peripheral location (i.e., subjects tended to move their eyes away from the cued location even when the lead dot appeared at that location). Notably, the analogous bias did not appear when subjects were, instead, asked to perform a temporal order judgment, thereby replicating Maylor's (1985) failure to find an effect of IOR on the speed of perceptual processing (see above).

If saccades show a directional bias in a temporal-orderjudgment-type paradigm, why is it that manual responses fail to reflect a similar bias? To the extent that manual and saccadic responses tap a common inhibitory mechanism, lateralized manual responses that are typically required in a temporal order judgment paradigm might be expected to show the same directional bias (quite apart from any effects on the speed of perceptual processing). In fact, there are limited conditions under which IOR may affect temporal order judgments. Measuring both accuracy and response latency in a temporal order judgment task, Gibson and Egeth (1994a) found that, when the onsets of the two target dots was nearly simultaneous (e.g., 14-msec onset asynchrony), neither RTs nor accuracies reflected the operation of IOR. However, when there was a longer delay between the onsets of the two targets dots, IOR occurred for RT (but not for accuracy).

Gibson and Egeth's (1994a) results demonstrate that IOR affects the speed to make a response but does not delay the arrival time of perceptual information from the previously cued location. This is consistent with a motor response view of IOR (see Klein, Schmidt, \& Müller, 1998). According to Klein and Taylor (1994), IOR is inhibition for making a response to a previously cued location. Whereas a saccadic movement requires that a location be selected for action-regardless of whether the visual input is bilateral or unilateral-when making a manual response with eyes fixed, the response is not explicitly to a particular location. Instead, with a manual response, the conditions under which a response is made to a particular location depend on the nature of the manual response itself (as with a localization response) or on the nature of the visual stimulus. Indeed, to the extent that detecting the onset of a unilateral visual stimulus requires an implicit localization response (see Klein \& Taylor, 1994), Gibson and Egeth's (1994a) results are exactly what would be predicted: The latency to make a temporal order judgment is affected by IOR when there is - at least initially-unilateral visual input.

The suggestion that IOR for manual responses may depend on unilateral visual input is consistent with limiting conditions under which IOR impacts the speed to make nonspatial target discriminations (note that these conditions may not necessarily hold when IOR is measured for the accuracy of nonspatial discriminations; see, e.g., Cheal, Chastain, \& Lyon, 1998). When a cuetarget paradigm is employed, ${ }^{5}$ IOR can occur for manual responses made on a nonspatial dimension-but only when the target is presented singly in the visual field (note that this stipulation does not hold for target discriminations that require a spatial localization response). When a single target appears following a peripheral cue, IOR is obtained for nonspatial discriminations of color (Lupiáñez, Milán, Tornay, Madrid, \& Tudela, 1997), identity (Danziger, Kingstone, \& Snyder, 1998; Pratt, Kingstone, \& Khoe, 1997), and line orientation (Handy, Jha, \& Mangun, in press). Given that attentional costs + benefits occur when a nonspatial discrimination target is presented with distractors (see, e.g., Yantis \& Johnston, 1990), this specificity of IOR for conditions of unilateral visual input is more parsimoniously accounted for by a motor bias account than by an attentional account. ${ }^{6}$

In summary, despite the fact that some findings are congruent with an attentional view of IOR, we feel that the motor view is more easily able to accommodate the literature as a whole. The motor bias view is able to account for (1) increased saccadic and manual latencies to a previously cued location, (2) the biasing of saccade direction in the absence of perceptual effects, (3) the occurrence of IOR for unilaterally presented targets that occur within the context of temporal order judgment paradigms, and (4) the occurrence of IOR for nonspatial target discriminations only under conditions of unilateral target presentation.

\section{INHIBITION OF RETURN: HOW IS THE INHIBITION GENERATED?}

Whereas the question of what is inhibited by IOR focuses on manipulations of the target task, the question of how IOR is generated focuses on manipulations of pretarget events (most notably, cuing procedures). In so doing, manual and saccadic RTs have been used as the dependent variables, under the presumption that these measures are equivalently sensitive to inhibitory operations of the cue. Accepting that manual and saccadic responses are valid measures of a general bias against responding to target information arising at the previously cued location, how is this bias established?

One possibility is that IOR depends on response inhibition (see Harvey, 1980). In the standard IOR paradigm, subjects are discouraged or else prohibited from making any overt response to the peripheral onset cue. This suggests that endogenous inhibition of a motor response to the cue may continue to operate at the time of target presentation. This view is consistent with anisotropies in the spatial distribution of the inhibitory effect, and, in fact, such anisotropies have been cited as evidence for a motor response view of IOR.

These anisotropies are defined by a within-hemifield spatial gradient of IOR that is bounded by the major meridia. In other words, the gradient does not cross the vertical meridian when cues and targets are presented along the horizontal and does not cross the horizontal meridian when cues and targets are presented along the vertical (Tassinari et al., 1987). Tassinari et al. (1987) intimated that these meridian effects arise from the ve- 
toing of a motor directional command. In particular, they argue that selective attention to the cue elicits a state of motor readiness that includes "general facilitation of all motor outputs potentially triggered or guided from the target area" (Tassinari et al., 1987, p. 68; for arguments that meridian effects derive from oculomotor, as opposed to general motor, preparation, see Hughes \& Zimba, 1987; Rizzolatti, Riggio, Dascola, \& Umiltà, 1987). Because of the requirement to suppress an overt response to the cue, this motor preparation-which includes a representation of cue direction-must be vetoed. This veto continues to be represented in the motor set at the time of target presentation. As a consequence, if the target occurs in the same direction as the cue, the veto and the target direction conflict, resulting in slowed RTs.

Although the motor inhibition view of the genesis of IOR is able to account for field anisotropies, it is contradicted by a plethora of data indicating that IOR occurs in response-response as well as in cue-target paradigms. Whereas a cue-target paradigm expressly requires that the subject inhibit a response to a stimulus event (the cue), in a response-response paradigm (also referred to as target-target or continuous-responding paradigms), IOR is revealed as slowed responses that are made to the same location as was a preceding response. Indicating first and second responses, respectively, IOR has been observed for the following combinations (1) manual- manual (Maylor \& Hockey, 1985, 1987; Posner, Cohen, Choate, Hockey, \& Maylor, 1984; Terry et al., 1994), (2) saccadic-manual (Posner et al., 1985; Rafal et al., 1989), and (3) saccadic-saccadic (Rafal et al., 1994; Vaughan, 1984). Despite the fact that a manual-saccadic combination has not been examined, these demonstrations force the conclusion that the genesis of IOR is not dependent on the inhibition of a (manual or saccadic) response. The implication regarding field anisotropies is that-contrary to the view of Tassinari, Biscaldi, Marzi, \& Berlucchi (1989)- these do not reflect how IOR is generated but, rather, what is inhibited: responses to the location (or toward the direction) of the preceding cue. In this regard, the anisotropies may be a manual analogue to the directional bias that Posner et al. (1985) observed for saccades.

Even though field anisotropies associated with the spatial distribution of IOR cannot speak to the generation of the inhibitory effect, Tassinari et al.'s (1989) conjecture that covert attention and motor control are intimately related is not without precedence (see, e.g., Klein, 1980; Posner, 1980; Posner \& Cohen, 1980; Rizzolatti et al., 1987). In fact, given that IOR can be obtained in both cue-target and response-response paradigms, the interrelation of covert attention and motor control is a necessary precondition of any viable account of IOR. One account that is able to satisfy this condition--by allowing for an interrelation of covert attention and oculomotor controlis the attentional view that gave rise to the term IOR.

Recall that the attentional view maintains that allocation of covert exogenous - but not endogenous-attention to a first signal generates IOR. This view makes no claims about responses to the first signal. IOR is seen to be a function of exogenous attention, so that whether an exogenous signal is ignored or else serves as the basis of a manual or saccadic response is of no consequence: So long as attention is captured by the peripheral luminance increment, IOR is generated.

The observation that saccades made in the absence of an exogenous signal (i.e., endogenously generated saccades) are capable of generating IOR (see, e.g., Posner \& Cohen, 1984; Rafal et al., 1989; Rafal et al., 1994) would seem to be at variance with the view that automatic allocation of attention in accordance with the first signal is a necessary condition for generating IOR. However, there is considerable evidence that both exogenously and endogenously driven saccades are intimately linked with covert attentional orienting. Covert attention is deployed in advance to the location of an executed saccade (see, e.g., Chelazzi et al., 1995; Shepherd, Findlay, \& Hockey, 1986). This occurs whether or not subjects are given incentive to attend to the saccade location (Henderson, 1990; Henderson, Pollatsek, \& Rayner, 1989; Hoffman \& Subramaniam, 1995; Inhoff, Pollatsek, Posner, \& Rayner, 1989; Kowler, Anderson, Dosher, \& Blaser, 1994; Posner, 1980; Rayner, McConkie, \& Ehrlich, 1978; Remington, 1980).

By thus asserting that IOR is a consequence of the prior allocation of exogenous covert attention, the attentional view presumes an opponent process relation between the facilitatory and inhibitory components revealed in the orienting paradigm. It follows that the two effects must, therefore, be consistently correlated. However, this does not appear to be the case. Despite being a proponent of the attentional view, Maylor (1985) reported IOR for saccadic RTs, in the absence of early facilitation; Lambert and Hockey (1991) demonstrated that - particularly with a high-salience cue-facilitation is eliminated by practice, whereas there is less marked diminution in the magnitude of IOR; and, these dissociations notwithstanding, direct attempts to define a role of covert attention in the genesis of IOR have likewise failed to provide strong supportive evidence (e.g., see the conflict between the doublecuing manipulations of Maylor, 1985; Posner \& Cohen, 1984; however, see also Tassinari \& Berlucchi, 1993).

Whereas the attentional view maintains that saccades are effective in generating IOR because they result in the exogenous allocation of covert attention, in an innovative twist, Rafal et al. (1989) reversed the argument by postulating that exogenous cues are effective in generating IOR because they result in saccadic programming. Consistent with the dissociations observed between IOR and facilitation, this oculomotor view makes functional dependence between covert exogenous attention and saccadic eye movements superfluous with respect to the genesis of IOR. More explicitly, this view asserts that IOR is not mediated via covert mechanisms but arises via direct activation of the oculomotor system; this activation may be independent of any effects that exogenous signals have on covert orienting (cf. Rafal \& Henik, 1994). 
Compelling evidence in favor of the oculomotor activation hypothesis was provided by Rafal et al. (1989). In a study that explored the conditions necessary to generate IOR, they varied both the nature of the first signal event (exogenous/endogenous) and eye movement instruction (eyes fixed, saccade execution, saccade preparation). At the beginning of a trial, subjects were presented with an exogenous cue to the left or the right of fixation or with a central arrow pointing to the left or the right of fixation. In the eyes-fixed condition, subjects maintained fixation and were required to attend to the cued location; in the saccade execution condition, subjects were required to saccade in the cued direction; in the saccade preparation condition, subjects were required to prepare a saccade in the cued direction but to execute it only if the target appeared next. On half of the trials, a target followed at a relatively short SOA, with $80 \%$ probability at the cued location. On the remaining half of the trials, the center fixation box brightened. This instructed subjects in the saccade execution condition to return their eyes to fixation and those in the saccade preparation condition to cancel the otherwise prepared saccade. On these double cue trials, the target then appeared at a long SOA with equal probability at the cued and uncued locations. Subjects responded to this target while maintaining fixation at center.

On the critical double-cue trials, IOR was observed for all conditions except the eyes-fixed/endogenous cue. Note that the eyes-fixed/endogenous cue and saccade preparation/endogenous cue conditions were identical, except that, in the latter, a saccade was prepared and then canceled. In spite of the similarity of the subjects' overt behavior in these two conditions, however, the saccade preparation/endogenous cue condition produced IOR, whereas the eyes-fixed/endogenous cue condition did not. If it is presumed that exogenous cues activate the oculomotor system even in the absence of an explicit requirement to prepare/execute a response and that endogenous cues do not, the results can be best summarized as follows: Any condition that activates an oculomotor program generates IOR; activation of an oculomotor program can be accomplished via automatic activation of the oculomotor system by the cue (as in the eyes-fixed/ exogenous cue condition), via explicit instructions to prepare a saccade to an exogenous or endogenous cue, or via the execution of a saccade to an exogenous or endogenous cue. This suggestion that saccadic programming is the critical basis of IOR is consistent with three converging lines of evidence that place the inhibition at the level of the SC.

\section{INHIBITION OF RETURN AND THE SUPERIOR COLLICULUS}

The SC and the frontal eye fields (FEF) comprise two parallel pathways responsible for producing saccadic eye movements (Albano, Mishkin, Westbrook, \& Wurtz, 1982; Albano \& Wurtz, 1982; Schiller, 1977; Schiller,
True, \& Conway, 1980). Part of the phylogentically older retinotectal pathway, the SC is responsible for reflexive orienting to visual targets (see, e.g., Mohler \& Wurtz, 1977; Sparks, 1978). In contrast, the FEF is responsible primarily for goal-directed saccades (see, e.g., Schiller, Sandell, \& Maunsell, 1987). The FEF exerts higher level control over the reflexive machinery of the SC (see, e.g., Guitton, Buchtel, \& Douglas, 1985). It does this through (1) direct connections to the SC (see, e.g., Braun, Weber, Mergner, \& Schulte-Monting, 1992; Sparks \& Porter, 1983 ) and (2) indirect connections via the caudate nucleus and substantia nigra pars reticulata (Hikosaka \& Wurtz, 1983a, 1983b, 1983c, 1985a, 1985b).

Each SC receives predominantly monocular input from the contralateral visual field, with greater representation from the temporal hemifield (nasal hemiretina) than from the nasal hemifield (temporal hemiretina) of the open eye. As such, under monocular viewing conditions, to the extent that IOR is collicular, it should be greater for targets that appear in the temporal than for those that appear in the nasal hemifield. Rafal et al. (1989) tested this prediction under the exogenous, eyes-fixed conditions described previously.

At the two earliest cue-target intervals, RTs were faster at the cued than at the uncued location; at the two longest cue-target intervals, there was IOR. The magnitude of the facilitatory effect did not differ by field (see, also, Shulman, 1984). Consistent with known connectivity of the retinotectal pathway, however, IOR - although significant in both fields-was greater for targets that appeared in the temporal than for those that appeared in the nasal hemifield. Interestingly, the finding that initial orienting of attention to the cued location did not show a field bias, whereas IOR did show such a bias, supports the dissociability of the facilitatory and inhibitory consequences of the first cue. Moreover, given that a temporal field bias is suggestive of retinotectal involvement, the finding that initial orienting to a predictive cue does not show a field bias argues against a common pathway with SC-generated saccadic eye movements. This is the case even though the first cue encouraged both endogenous and exogenous control (by virtue of being a predictive luminance increment).

The second line of evidence that converges with SC involvement in the genesis of IOR comes from neuropsychological studies of individuals afflicted with progressive supranuclear palsy (PSP). Like Parkinson's disease, PSP is associated with degeneration of the basal ganglia and consequent motor impairment. However, ophthalmoparesis from degeneration of the SC and peritectal region is pathognomic to PSP. These individuals demonstrate a marked impairment in making voluntary saccades, particularly in the vertical plane. Posner et al. (1985) argued that, to the extent that IOR is associated with the oculomotor system, (1) PSP patients should reveal deficits in IOR that are greater in the vertical than in the horizontal plane, and (2) such deficits should be tied to collicular damage and should, therefore, not be a consequence of motor impairment associated with basal gan- 
glia degeneration in Parkinson's disease or related to lesions of the frontal or the parietal cortex.

Posner et al. (1985) compared the performance of PSP patients, Parkinsonian, frontal, parietal, and normal controls in a study that presented a brightening at one of two peripheral locations. Early detection targets appeared with $80 \%$ probability at the location of the first cue. In the absence of an early target, the center location brightened, and a late target appeared with equal probability at the two peripheral locations. Consistent with their predictions, the authors reported IOR for all groups in the horizontal plane, no difference in IOR for the vertical versus horizontal plane in Parkinson patients, and no IOR in the vertical plane in PSP patients.

A collicular basis of IOR is likewise supported by a third line of evidence that results from Abrams and Dobkin's (1994) application of additive factors logic (cf. Sternberg, 1969) to the study of IOR and the gap effect. The gap paradigm presents subjects with a central fixation stimulus that can be offset at various intervals, relative to the onset of a peripheral saccade target. When the fixation stimulus is offset prior to, or else coincident with, the onset of the saccade target, RTs are reduced, relative to cases in which the fixation stimulus remains visible (see, e.g., Fischer \& Ramsperger, 1984; Kingstone \& Klein, 1993; Reulen, 1984; Reuter-Lorenz, Hughes, \& Fendrich, 1991; Saslow, 1967). Several lines of evidence converge on SC mechanisms as the basis for the facilitation of saccadic RT that occurs upon the offset of a fixated stimulus (i.e., the gap effect): (1) The threshold current required to elicit a saccade via the SC is increased during active fixation (Sparks \& Mays, $1983)$; (2) fixation cells in the intermediate rostral SC inhibit the remaining intermediate $\mathrm{SC}$ during active fixation (Munoz \& Wurtz, 1992, 1993a, 1993b); and (3) activity in these fixation cells is correlated negatively with the latency to make saccades in the gap paradigm, so that the maximum decrease in discharge rates corresponds with the fastest saccades (Dorris \& Munoz, 1995). According to additive factors logic, if IOR and the gap effect depend on common neural processes/mechanisms, they should interact.

Abrams and Dobkin (1994) presented subjects with an onset cue to the left or right of fixation, followed by an onset cue at fixation. On overlap trials, the fixation stimulus remained visible; on 0 -msec gap trials, the fixation point was extinguished simultaneously with saccade target onset; on 200-msec gap trials, the fixation stimulus was extinguished $200 \mathrm{msec}$ prior to saccade target onset. The saccade target occurred with equal probability at one of the two peripheral locations. Consistent with a common, collicular, mechanism, the authors reported a reliable IOR effect, a reliable gap effect, and a significant interaction of IOR with gap condition (a larger gap effect in the 0 - and 200-msec gap conditions than in the overlap condition).

Taken together, the weight of evidence falls in favor of the oculomotor view of the genesis of IOR: Whether an oculomotor program is elicited automatically via the onset of an exogenous signal or endogenously via the preparation to make a saccade, inhibition is established for subsequent saccadic or manual responses (cf. Rafal et al., 1989). On the basis of converging evidence of a temporal field bias for IOR, deficient IOR along the vertical meridian for PSP patients, and the interaction of IOR with the gap effect, it appears that the oculomotor machinery of the SC plays a key role.

Is an SC basis of IOR easily reconciled with the suggestion that IOR may be a motor bias? Tanaka and Shimojo (1996) indicated that dependence of IOR on target localization is consistent with a role of the dorsal pathway. On the output end, the SC is part of this pathway. As such, the SC presents a possible neural basis for linking the methods by which IOR is generated to the means by which it can be measured. However, a coherent picture of the inhibitory effect must account for the ability of IOR to be generated by endogenously as well as by exogenously activated oculomotor programs and for the ability of this activation to produce an inhibitory effect that is reflected in a bias against responding to targets that appear at the cued location.

\section{SUPERIOR COLLICULUS MAPPING OF INHIBITION OF RETURN? ACTIVATION AND ACCESS}

Neurophysiological data (see Mohler \& Wurtz, 1976) indicate that visual response output from the retinotopically organized (Colby, 1991) superficial layers of the $\mathrm{SC}$ converges with two-dimensional motor output from the deep layers (Hepp, VanOpstal, Straumann, Hess, \& Henn, 1993) to create an intermediate layer mapping of motor error (Segraves \& Park, 1993; Sparks \& Porter, 1983; see also Krommenhoek, VanOpstal, Gielen, \& VanGisbergen, 1993, and Massone, 1994, for neural network models) that drives brainstem oculomotor centers. ${ }^{7}$ Vector coding of saccade metrics in the intermediate layer of the SC can be influenced by topographic connectivity that exists between FEF and SC. For example (see Schall, 1997, for an overview), the lowest thresholds for antidromic stimulation of FEF sites occur at SC sites that code the same vector; simultaneous stimulation of FEF and SC sites results in an elicited saccade that is the sum of the vectors from each stimulation site weighted by the applied current; and, in the absence of competing activation, electrically evoked saccades from the FEF excite $\mathrm{SC}$ saccade cells of the intermediate layers that code the same vector (Schlag-Rey, Schlag, \& Dassonville, 1992). Given this connectivity, a role of the $\mathrm{SC}$ in the genesis of IOR is not at variance with the ability of endogenously generated saccades to either generate or reveal the effects of the inhibition.

In particular, because IOR is an environmentally coded effect that influences motor responses based on target localization, to the extent that it may be $\mathrm{SC}$ based, the representation of the inhibition would be expected at the level 
of the intermediate layer. If this reasoning is correct, any response that determines activation within this map should be capable of producing IOR; any response that depends on the level of activation within that map should be capable of reflecting the effects of IOR. Topographical connectivity of the FEF and SC indicates that both endogenous and exogenous saccadic programming involves access to this intermediate layer SC map, so both should be able to lay down a neural representation and be sensitive to the effects of the inhibition.

This speculation regarding an SC basis of IOR is seductive because of its internal consistency: IOR appears to be generated by the activation of a saccadic vector in the intermediate layers of the colliculus, and it is in precisely such a visuomotor map that a neural representation of inhibition (e.g., decreased neural activity/responsiveness) could interfere with directed responses to a previously stimulated location. However, there are holes in the data set from which this speculation derives. To the extent that IOR may be SC based, how does a representation of inhibition in the oculomotor system impact manual RTs? Is there evidence to suggest that manual and saccadic responses generate and measure the effects of inhibition on the same substrate? As will be seen, it is not clear whether the bias against responding to a previously cued location is a purely motoric effect and/or whether it represents slowed motor responding to a peripheral visual stimulus, whether IOR is generated by activation of an oculomotor program or due to activation of any ocular or nonocular directed response (which would have implications for how SC-based effects impact manual RTs; cf. Werner, Dannenberg, \& Hoffman, 1997), and, perhaps most crucially, whether what is inhibited might depend critically on how IOR is generated.

\section{GENERATING AND MEASURING INHIBITION OF RETURN: TOWARD A COMPLETE ASSESSMENT}

As indicated previously, the motor bias account of IOR derives considerable support from the body of literature manipulating the manner by which IOR is measured. However, all of the studies reviewed above demonstrated IOR using RT or directional preference for responding to peripheral onset targets. Even accepting the supposition that IOR is a bias for responding to stimuli from a previously cued location, it is unclear whether this bias is strictly motor or whether it reflects slowed motor responding to peripheral visual input (i.e., is visuomotor). Particularly if a role of the intermediate SC is assumed, the representation of inhibition in an integrated visuomotor map could rest on inhibitory input from the motor layers themselves and/or from the integration of signals deriving from both the motor and the visual layers. Given that a peripheral target represents visual stimulation at the location to which a response must be directed, the use of such targets confounds purely motor and visuomotor processes.
At first reading, our use of visuomotor in this context may not be obviously distinct from a purely visualperceptual process of the sort we discussed with reference to attentional accounts of IOR. Indeed, the suggestion that IOR may reflect inhibition for directing a response to a peripheral visual source suggests that there may, in fact, be a perceptual deficit for coding visual information. However, our use of the term visuomotor is intended to capture the view that, if there is a perceptual deficit, it is unrelated to visuospatial attentional mechanisms (by virtue of the fact that IOR is not consistently revealed in paradigms that assess the speed or quality of perceptual processing). Instead, any perceptual deficit is related to visuomotor integration wherein visual information arising at a previously cued location is relatively less effective in directing a motor response than is visual information arising at a previously uncued location. In other words, we are distinguishing a perceptual deficit owing to inhibited attentional orienting from a perceptual deficit that is tied to the integration of a visual percept with a required motor response (i.e., visuomotor integration).

Abrams and Dobkin (1995) performed a study that can be construed as a test of visuomotor and motor bases of IOR. ${ }^{8}$ By examining saccadic latencies in response to exogenous versus endogenous motor command signals, Abrams and Dobkin (1995) presented subjects with a peripheral onset cue to the left or the right of fixation; no response was required. This was followed by an onset cue at fixation. A saccade signal was then presented, indicating left and right locations with equal probability. In separate blocks, this saccade signal was exogenous (the onset of a peripheral luminance target) or endogenous (a directional arrow presented at fixation). In the case of an exogenous command, the directed motor response was contingent on processing the exogenous visual signal from a potentially inhibited location (hence, was what we will term visuomotor); in the case of the endogenous command, the directed motor response was identical but occurred without requisite visual processing from a potentially inhibited location (hence, was strictly motoric with respect to the peripheral location).

Abrams and Dobkin (1995) found a significant 24msec IOR effect in the exogenous command condition and a significant 9-msec IOR effect in the endogenous command condition. The fact of significant IOR for both command signals argues that there was an overall motor bias against responding to the cued location, irrespective of whether visual information was presented at that location. However, the 15-msec difference in the magnitude of IOR in the two signal conditions indicated that the inhibitory effect observed with peripheral onset targets was not accounted for entirely by motor inhibition: There was an additional visual inhibitory influence associated with peripheral visual processing and/or integration of visual information with the motor response to the cued location. ${ }^{9}$

Apart from qualifying the motor bias view of IOR. Abrams and Dobkin's (1995) study introduces the notion 
that what is inhibited in IOR may depend, in part, on how a response is elicited (i.e., exogenously or endogenously). Their results indicate that, at least for saccades, IOR for making an identical speeded response to a peripheral location represents inhibition for visuomotor integration (cf. Klein \& Taylor, 1994) when the imperative signal is exogenous and motor inhibition when the imperative signal is endogenous.

What is not clear on the basis of Abrams and Dobkin's (1995) results is whether IOR for a speeded manual response might also demonstrate a visuomotor and/or motor basis, depending on whether the response is commanded exogenously or endogenously. If the same pattern did not emerge for manual responses as was observed for saccadic responses, this would challenge the assumption that manual and saccadic RTs are different rulers for measuring the same inhibitory effects. Given that what is inhibited in saccadic RT depends on how the response is elicited, it seems a reasonable conjecture that what is inhibited might also depend on what response is elicited. Are visuomotor and motor inhibition represented by IOR for manual responses elicited under exogenous and endogenous control, respectively? Or might the differences between exogenous and endogenous control be specific to oculomotor responses (perhaps owing to the accuracy of a saccadic response that depends on the adequacy of, and not just on the fact of, target localization)? In other words, is IOR a unitary construct across dependent measures (manual versus saccadic) or within a given dependent measure (e.g., motor and visuomotor effects were observed by Abrams \& Dobkin, 1994)?

Questions regarding the role that directed motor responses may play in the genesis of IOR can also be asked. Consider that, in a cue-target paradigm, IOR does not occur following endogenous cues but does occur following exogenous cues. This is a defining feature of the inhibitory effect. Recall that, in establishing the importance of saccadic programming for the generation of IOR, Rafal et al. (1989) relied on the critical finding that IOR occurred for all conditions except that which required covert orienting to an endogenous cue. It is tempting to conclude that exogenous cues enjoy a privileged status in their ability to activate an oculomotor program and that endogenous cues can do so only under the demands of an instructional set (i.e., when subjects are explicitly required to use the cues to program and/or execute a saccadic response). However, given that endogenous and exogenous cues not only differ in the nature of the signal itself but are also associated with different forms of covert attentional orienting, it is possible that endogenous covert orienting interferes with the ability to observe IOR to endogenous signals.

Indeed, this potential problem is exacerbated in other studies (e.g., Posner \& Cohen, 1984) for which the comparison of exogenous and endogenous cuing has been confounded with spatial probability manipulations. In particular, endogenous (symbolic) cues typically are given predictive validity for the subsequent target location, whereas exogenous cues are not. The rationale for this difference is as follows. Whereas an exogenous cue is expected to capture attention automatically, endogenous cues require symbolic interpretation. By making a symbolic cue predictive of target location, subjects are encouraged to interpret the cue and to allocate resources accordingly. Although a motivated feature of endogenous cuing paradigms, this use of a probability manipulation with endogenous but not with exogenous cues clouds the comparison of exogenous/endogenous signals with exogenous/ endogenous covert orienting. In particular, it is unclear whether endogenous cuing fails to produce IOR because the cue is predictive of target location and/or because the signal (i.e., the cue itself) is symbolic. By making endogenous signals highly probable, there is an a priori assumption that covert attentional orienting is critical to the comparison of exogenous and endogenous cuing.

Consider the possibility that an ignored uninformative exogenous cue may generate IOR for responses made to a peripheral onset target because both the cue and the target stimuli are defined by a luminance increment, and not because the cue is peripheral stimulation per se (cf. Folk, Remington, \& Johnston, 1992; Yantis, 1993; Yantis \& Jones, 1991). In other words, the knowledge that a response is required to a luminous onset target might establish a priority tag wherein the generation of a motor response occurs to any onset event. When stimulated by an unpredictive cue, such motor activation could, in turn, lead to IOR. Accepting this as plausible, in a cue-target paradigm that requires subjects to respond to endogenous signals as the target, the response might also set up an equivalent priority tag for endogenous signals that are used as the cue. To determine whether this might be the case, it is necessary to employ unpredictive exogenous and endogenous commands as first (e.g., cue) and second (e.g., target) signals. Is it possible that withholding a response to an endogenous signal that is associated with a saccadic or manual motor command (as opposed to an endogenous covert orienting command) might be capable of generating IOR - perhaps via automatic motor activation?

With respect to this issue of activating the motor response system, Rafal et al.'s (1989) study suggested that it is oculomotor rather than general motor response activation that generates IOR. In a control study that resembled the endogenous cue/saccade preparation condition, Rafal et al. (1989) had subjects prepare, and sometimes cancel, a directed manual response with the left hand. On half of the trials, the arrow cue was followed by an onset target that appeared with $80 \%$ probability at the cued location, and subjects were required to make a speeded localization response with the left hand. On the remaining half of the trials, the center box brightened, indicating that subjects were to cancel the prepared left-hand response and that a target demanding a detection response with the right hand was equally likely at the two peripheral target locations. IOR was assessed following the cancellation of the prepared response.

Unlike cases in which a prepared saccadic response was canceled, the cancellation of a manual response did not produce IOR. Although this is strong evidence that 
oculomotor activation is necessary for the generation of IOR and that manual response preparation is not sufficient, it does not allow for the possibility that manual response execution is sufficient to generate IOR. As such, the interest in the ability of exogenous and endogenous command signals to generate IOR should be extended to include not only conditions in which subjects withhold a response to the first signal but also conditions in which they execute a manual response. Also, having subjects execute a saccadic response to exogenous or endogenous first signals would allow examination of the effects of specifically oculomotor response execution.

Beyond questions asked about the particular means by which IOR is measured and the methods by which it is generated, there is a final critical question as to whether these interact. In other words, does the manner by which IOR is generated determine what is inhibited? The possibility that such interactions may be fundamental to a characterization of IOR is suggested by a study performed by Rafal et al. (1994) in which they examined latencies of pro- and anti-saccades under conditions in which IOR was generated by (1) an ignored exogenous cue, (2) a saccade to an exogenous cue, and (3) a saccade to an endogenous cue. Where a pro-saccade is an eye movement to the location of an onset target and an anti-saccade is an eye movement of equal amplitude but opposite direction as an onset target, the rationale for comparing the two is that both require the detection of a peripheral stimulus but the motoric response to the peripheral stimulus is opposite in the two conditions.

When subjects withheld a response to an exogenous cue, saccadic latencies were longer for targets arising at the cued location for both pro- and anti-saccades. This suggests that the inhibition is for making a response on the basis of target information presented at the cued location: RTs were slowed whether the response was in the direction of the target (pro-saccade) or in the direction opposite the target (anti-saccade). The same was true when subjects made a saccade to the exogenous signal and then returned fixation to center before target onset. On the other hand, when subjects saccaded to an endogenous signal, returned gaze to fixation, and then made a pro- or anti-saccade in response to an onset target, saccadic latencies were longer for targets arising at the cued location, but only for pro-saccades.

Why did saccades to an endogenous first signal fail to produce IOR for anti-saccades? Rafal et al. (1994) suggested that the endogenous saccade to the first signal may have produce (1) an inhibition associated with processing a peripheral visual target (i.e., this could represent visuomotor inhibition wherein subjects are slow to make a response based on target information presented at the cued location, not necessarily slow to direct a response to that location) that would affect both pro- and anti-saccades and (2) an inhibition associated with a motor bias favoring responses away from the cued location/ toward the uncued location, which would counter the visuomotor processing inhibition in the anti-saccade but not in the pro-saccade condition. When peripheral visual processing was circumvented by having subjects saccade to an endogenous signal that was followed by another endogenous saccade signal (i.e., as opposed to an onset signal that directed an anti-saccade to the mirror-symmetric location), IOR was observed. This corroborates the view that endogenous saccades may generate inhibition based on guiding a response via visual stimulation at the cued location and inhibition for actually responding to the cued location. In summary, generation of IOR by an exogenous signal produces inhibition associated with making responses based on peripheral visual information presented at a previously cued location (i.e., visuomotor inhibition); generation of IOR by an endogenous saccade produces inhibition associated with both making responses based on visual information presented at a previously cued location (i.e., visuomotor inhibition) and making responses to (i.e., motor inhibition) a previously cued location. ${ }^{10}$

The exact explanation of Rafal et al.'s (1994) results notwithstanding, the fact that what is inhibited may be determined not only by the response that establishes IOR but also by the signal that commands the response (exogenous, endogenous) suggests a rich tapestry of possible interactions. Although critical research questions have been raised in the preceding discussion, to help visualize questions that remain regarding the generation, measurement, and possible interaction of these factors under conditions of exogenous and endogenous control, cells in which IOR has been obtained in the literature are indicated in Figure 2.

Where S1 refers to the stimulus conditions used to generate IOR and S2 refers to stimulus conditions used to direct a speeded response intended to measure the effects of IOR, the key to filling out the design depicted in Figure 2 is examining the difference in RT when S1 and S2 signal the same rather than different locations (i.e., a measure of IOR) under each combination of unpredictive $\mathrm{S} 1$ (exogenous, endogenous) and S2 (exogenous, endogenous) and each $\mathrm{S} 1-\mathrm{S} 2$ response combination (no response-manual, manual-manual, saccadic-manual, no responsesaccadic, manual-saccadic, saccadic-saccadic). Under what conditions is IOR established? Under what conditions is it measured? How do these interact?

\section{PREDICTIONS STEMMING FROM CURRENT VIEWS OF INHIBITION OF RETURN}

On the strength of preceding arguments regarding what is inhibited by IOR and how IOR is generated, it is possible to outline predictions in the context of the cells depicted in Figure 2. First, consider the issue of what is inhibited by IOR. The weight of evidence in the literature suggests that IOR represents a motor inhibition for responding to a previously cued location. As already noted with respect to manual RTs, only peripheral visual targets have been employed. As such, the literature predicts that a motor response bias will be reflected in the speed to make 


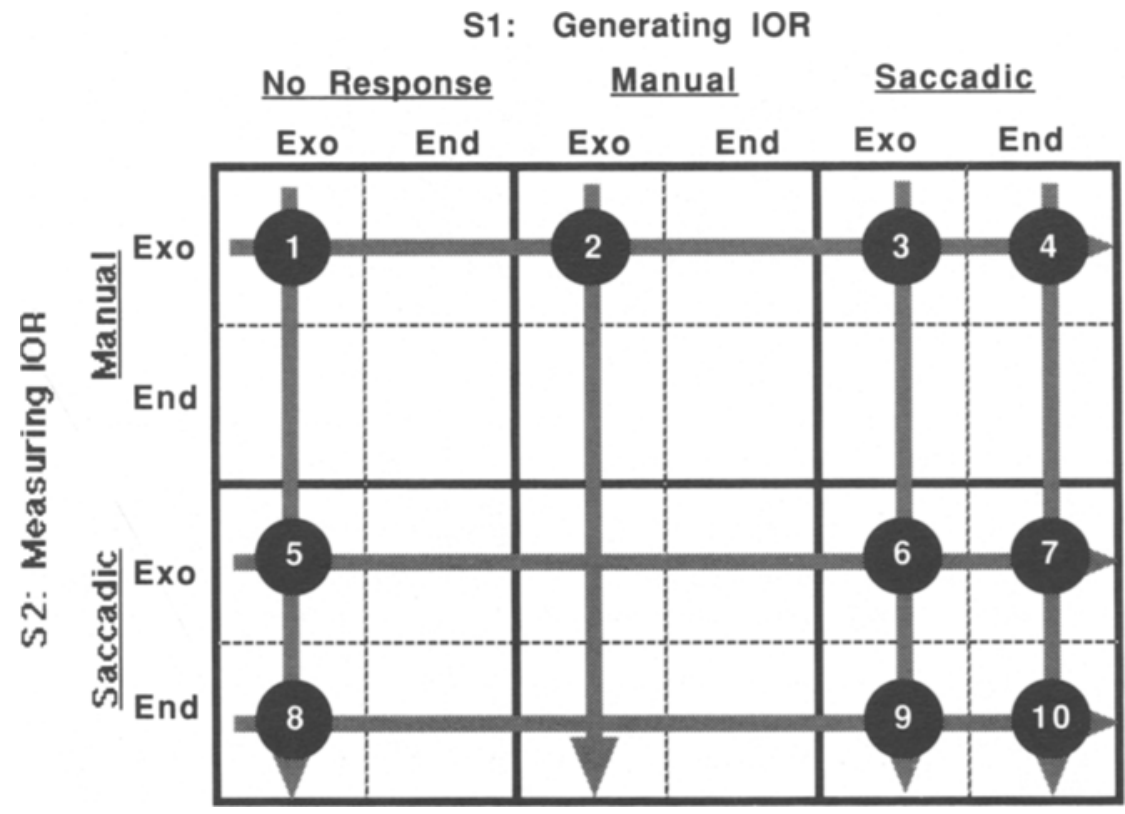

Figure 2. Summary of the literature and predictions based on a motor account of IOR. Note that endogenous in this table refers to an unpredictive symbolic signal. The arrows indicate the stimulus/response combinations for which a prediction is made. In particular, the three horizontal arrows indicate that IOR should be measured by manual responses to exogenous S2s and by saccadic responses to exogenous and endogenous S2s. The four vertical arrows indicate that IOR should be generated when no response is made to an exogenous $S 2$, when a manual response is made to an exogenous $\$ 2$, and when a saccadic response is made to an exogenous or an endogenous $S 2$. The two cells that have no arrow running through them are those for which the $S 1$ stimulus/response combinations are not predicted to generate IOR and for which the $\mathbf{S 2}$ stimulus/response combinations are not predicted to be sensitive to the effects of IOR. Places where the arrows intersect mark locations where IOR should be observed: In order for IOR to be revealed, the $S 2$ stimulus/response combination must be sensitive to any inhibitory effects that are present $a n d$, in order for inhibitory effects to be present, the $\mathrm{S} 1$ stimulus/response combination must be capable of generating inhibition. IOR is not predicted for any other cells. The circles numbered 1-10 in the table represent all the combinations of S1/S2 conditions that have been tested for IOR; the black coloring indicates that significant IOR effects were observed (i.e., IOR was significant in all the cases tested). Examples of studies that have shown the effects indicated by the black circles (according to the numbered cell) include: (1) Berlucchi et al., (1989), Gibson and Egeth (1994a, 1994b), Lambert and Hockey (1991), Maylor (1985), Pontefract and Klein (1988), Posner and Cohen (1984), Posner et al. (1985), Possamai (1986), Pratt et al. (1997), Reuter-Lorenz et al. (1996), Schmidt (1996a), Tassinari et al. (1987), Tassinari and Berlucchi $(1993,1995)$, Tassinari et al. (1989), Tipper et al. (1991), Tipper et al. (1994); (2) Kwak and Egeth (1992), Maylor and Hockey (1985, 1987), Posner et al. (1984), Tanaka and Shimojo (1996), Terry et al. (1994); (3) Rafal. et al. (1989); (4) Posner and Cohen (1984), Posner et al. (1985), Rafal et al. (1989); (5) Abrams and Dobkin (1994, 1995), Maylor (1985), Rafal et al. (1994), Reuter-Lorenz et al. (1996); (6) Rafal et al. (1994), Vaughan (1984); (7) Rafal et al. (1994); (8) Abrams and Dobkin (1995); (9) Rafal et al. (1994); (10) Rafal et al. (1994).

manual responses to exogenous signals; however, there are no grounds for predicting the same effect for manual responses made to endogenous signals. In contrast, given that IOR measured by saccadic RTs does not depend on peripheral visual information (cf. Abrams \& Dobkin, 1995; Rafal et al., 1994), IOR is expected to occur for saccades made to both exogenous and endogenous commands. These predictions regarding the measurement of IOR are depicted by arrows across the rows of Figure 2 .

Consider now the conditions under which IOR is expected to be generated. Evidence seems to be consistent with the view that IOR is generated by activation of the oculomotor system. More particularly, IOR is generated by signals that elicit an oculomotor program. To the extent that exogenous signals may automatically elicit saccadic programming, the occurrence of an exogenous signal should be capable of generating IOR, irrespective of the response requirements associated with that signal. However, there is no clear evidence on which to ground predictions for endogenous signals. Certainly, when an endogenous signal is used to command a saccadic response, IOR should be generated (i.e., because the execution of 
the endogenously commanded saccade requires that there be a saccadic program). In the absence of any evidence that endogenous cues can establish priority tags or otherwise activate saccadic programming, there is no reason to assume that endogenous signals that require no response or else that require a manual response should likewise be capable of generating IOR. The predictions regarding those conditions believed to be capable of generating IOR are depicted by arrows down the columns of Figure 2 .

\section{DIRECTIONS FOR FUTURE RESEARCH}

The combined predictions for the generation and measurement of IOR are represented in Figure 2 and, superimposed on this figure, is a representation of those cells for which IOR has been observed in the literature. Not surprisingly, the data on which views of the generation and measurement of IOR have been based are consistent with the logical necessity that, to observe IOR in human performance, (1) the inhibition must somehow be generated, and (2) the task used to measure the inhibition must be sensitive to (affected by) IOR. In other words, IOR has been observed in cells for which S1 stimulus/response conditions are capable of generating a saccadic program and S2 stimulus/response conditions are capable of measuring the presumed visuomotor and/or motor bias against responding to the cued location. Indeed, this view would posit that IOR will occur (note that IOR is present when generated but might not be observed if the wrong measuring tool is used) only in those cells for which predictions for the generation of IOR converge with predictions for the measurement of IOR (i.e., in the cells of Figure 2 for which the arrows intersect).

As Figure 2 demonstrates, views of IOR that have been derived from the existing literature are based on tests of only 10 of 24 possible experimental cells. To fully understand the nature of IOR and its possible mechanisms, it would seem that systematic study of the conditions that generate IOR and those that measure its impact is warranted. Current conceptualizations will be challenged to the extent that IOR is obtained in those cells for which IOR is not predicted to occur and also to the extent that IOR may not be obtained in cells for which effects are predicted to occur.

\section{REFERENCES}

Abrams, R. A., \& Dobkin, R. S. (1994). The gap effect and inhibition of return: Interactive effects on eye movement latencies. Experimental Brain Research, 98, 483-487.

AвRAMS, R. A., \& DовкIN, R. S. (1995). Inhibition of return: Effects of attentional cuing on eye movement latencies. Journal of Experimental Psuchologv: Human Perception \& Performance. 20. 467-477.

Albano, J. E., Mishkin, M., Westbrook, L. E., \& Wurtz, R. H. (1982). Visuomotor deficits following ablation of monkey superior colliculus. Journal of Neurophysiologi, 48, 318-337

Albano, J. E., \& WurtZ, R. H. (1982). Deficits in eye position following ablation of monkey superior colliculus, pretectum and posteriormedial thalamus. Joumal of Neurophtsiolog: 48, 318-337.

Bfri.ucchi, G., Tassinari, G., Marzi, C. A., \& DiStffano, M. 1989 )
Spatial distribution of the inhibitory effect of peripheral non-informative cues on simple reaction time to non-fixated visual targets. Neuropsychologia, 27, 201-221.

Biederman, I., \& CoOPer, E. E. (1992). Size invariance in visual object priming. Journal of Experimental Psychology: Human Perception \& Performance, 18, 121-133.

Braun, D., Weber, H., Mergner, T., \& Schulte-Monting, J. (1992). Saccadic reaction times in patients with frontal and parietal lesions. Brain, 115, 1359-1386.

Breau, L., Mondor, T., \& Milliken, B. (1995). Auditory inhibition of return. Poster presented at the annual meeting of the Canadian Society for Brain, Behavior, and Cognitive Science, Halifax, Nova Scotia.

Briand, K. A., \& KLEIN, R. M. (1987). Is Posner's "beam" the same as Treisman's "glue"?: On the relation between visual orienting and feature integration theory. Journal of Experimental Psychology: Human Perception \& Performance, 13, 228-241.

Bushnell, M. C., Goldberg, M. E., \& Robinson, D. L. (1981). Behavioral enhancement of visual responses in monkey cerebral cortex: I. Modulation in posterior parietal cortex related to selective visual attention. Journal of Neurophysiology, 46, 755-771.

Cheal, M., Chastain, G., \& Lyon, D. R. (1998). Inhibition of return in identification tasks. Visual Cognition, 5, 365-388.

Chelazzi, L., Biscaldi, M., Corbetta, M., Peru, A., Tassinari, G., \& BERLUCCHI, G. (1995). Oculomotor activity and visual spatial attention, Behavioural Brain Research, 71, 81-88.

COLBY, C. L. (1991). The neuroanatomy and neurophysiology of attention. Journal of Child Neurology, 67, S90-S1 18.

Corbetra, M., Miezin, F. M., Dobmeyer, S., Shulman, G., L., \& PETERSEN, S. E. (1990). Attentional modulation of neural processing of shape, color, and velocity in humans. Science, 248, 1556-1559.

Danziger, S., Kingstone, A., \& SNyder, J. J. (1998). Inhibition of return to successively stimulated locations in a sequential visual search paradigm. Journal of Experimental Psychology: Human Perception \& Performance, 24, 1467-1475.

Dorris, M. C., \& Munoz, D. P. (1995). A neural correlate for the gap effect on saccadic reaction times in monkey. Journal of Neurophysiology, 73, 2558-2562

Downing, C. J. (1988). Expectancy and visual-spatial attention: Effects on perceptual quality. Journal of Experimental Psychology: Human Perception \& Performance, 14, 188-202.

Downing, C. J., \& Treisman, A. (1995). The shooting line illusion: Attention or apparent motion? Investigative Ophthalmology \& Visual Science, 36, S856.

Downing, P. E., \& Treisman, A. M. (1997). The line-motion illusion: Attention or impletion? Journal of Experimental Psychology: Human Perception \& Performance, 23, 768-769.

DUNCAN, J. (1984). Selective attention and the organization of visual information. Journal of Experimental Psychology: General, 113, 501-517.

FISCHER, B., \& RAMSPERgER, E. (1984). Human express saccades: Extremely short reaction times of goal directed eye movements. Experimental Brain Research, 55, 232-242.

Foley, J. M., \& Boynton, G. M. (1993). Forward pattern masking and adaptation: Effects of duration, interstimulus interval, contrast, and spatial and temporal frequency. Vision Research, 33, 959-980.

Folk, C. L., Remington, R., \& Johnston, J. C. (1992). Involuntary covert orienting is contingent on attentional control settings. Journal of Experimental Psychology: Human Perception \& Performance, 18 , 1030-1044.

Fuentes, L. J., Vivas, A. B., \& Humphreys, G. W. (in press). Inhibitory tagging of stimulus properties in inhibition of return: Effects of semantic priming and flanker interference. Quarterly Journal of Experimental Psychology.

GibSON, B. S., \& EGETH, H. (1994a). Inhibition and disinhibition of return: Evidence from temporal order judgments. Perception \& Pstchophysics, 56, 669-680.

Gibsion, B. S., \& Egeth, H. (1994b). Inhibition of return to object-based and environment-based locations. Perception \& Psychophysics, 55. 323-339.

Glitton, D., Buchtel, H. A., \& Dougilas. R. M. (1985). Frontal lobe 
lesions in man cause difficulties in suppressing reflexive glances and in generating goal-directed saccades. Experimental Brain Research, 58, 455-472.

Handy, T. C., JHA, A. P., \& Mangun, G. R. (in press). Promoting novelty in vision: Inhibition of return modulates perceptual-level processing. Psychological Science.

HARVEY, N. (1980). Non-informative effects of stimuli functioning as cues. Quarterly Journal of Experimental Psychology, 32, 413-425.

Hawkins, H. L., Hillyard, S. A., Luck, S. J., Mouloua, M., Downing, C. J., \& Woodward, D. P. (1990). Visual attention modulates signal detectability. Journal of Experimental Psychology: Human Perception \& Performance, 16, 802-811

Hawkins, H. L., Shafto, M. G., \& Richardson, K. (1988). Effects of target luminance and cue validity on the latency of visual detection. Perception \& Psychophysics, 44, 484-492.

HENDERSON, J. M. (1990). The allocation of visual-spatial attention prior to a saccadic eye movement. Paper presented at the annual meeting of the Psychonomic Society, New Orleans.

Henderson, J. M., Pollatsek, A., \& Rayner, K. (1989). Covert visual attention and extrafoveal information use during object identification. Perception \& Psychophysics, 45, 196-208.

Hepp, K., VanOpstal, A. J., Straumann, D., Hess, B. J., \& Henn, V. (1993). Monkey superior colliculus represents rapid eye movements in a two-dimensional motor map. Journal of Neurophysiology, 69, 965-979.

Hikosaka, O., Miyauchi, S., \& Shimojo, S. (1993a). Focal visual attention produces illusory temporal order and motion sensation. Vision Research, 33, 1219-1240.

Hikosaka, O., MiYauchi, S., \& Shimojo, S. (1993b). Visual attention revealed by an illusion motion. Neuroscience Research, 18, 11-18.

Hikosaka, O., Miyauchi, S., \& Shimojo, S. (1993c). Voluntary and stimulus-induced attention detected as motion sensation. Perception, 22, 517-526.

Hikosaka, O., \& WURTZ, R. H. (1983a). Effects on eye movements of a GABA agonist and antagonist injected into monkey superior colliculus. Brain Research, 272, 368-372.

HiKoSAKA, O., \& WURTZ, R. H. (1983b). Visual and oculomotor functions of monkey substantia nigra pars reticulata; III. Memory-contingent visual and saccade responses. Journal of Neurophysiology, 49, 1269-1284.

HikosaKa, O., \& WURTZ, R. H. (1983c). Visual and oculomotor functions of monkey substantia nigra pars reticulata: IV. Relation of substantia nigra to superior colliculus. Journal of Neurophysiology, 49, 1285-1301.

HiKosAKA, O., \& WuRTZ, R. H. (1985a). The basal ganglia. In R. H. Wurtz \& M. E. Goldberg (Eds.), The neurobiology of saccadic eye movements (pp. 257-281). Amsterdam: Elsevier.

HIKosaKA, O., \& WURTZ, R. H. (1985b). Modification of saccadic eye movements by GABA-related substances: I. Effect of muscimol and bicuculline in monkey substantia nigra pars reticulata. Journal of Neurophysiology, 53, 266-291.

Hoffman, J. E., \& Subramaniam, B. (1995). The role of visual attention in saccadic eye movements. Perception \& Psychophysics, 57, 787-795.

Hughes, H. C., \& ZimBA, L. D. (1987). Natural boundaries for the spread of directed visual attention. Neuropsychologia, 2, 5-18.

Inhoff, A. W., Pollatsek, A., Posner, M. I., \& Rayner, K. (1989). Covert attention and eye movements during reading. Quarterly Journal of Experimental Psychology, 41 A, 63-89.

JoNIDES, J. (1980). Towards a model of the mind's eye's movement. Canadian Journal of Psychology, 34, 103-112.

JONIDES, J. (1981). Voluntary versus automatic control over the mind's eye's movement. In J. B. Long \& A. D. Baddeley (Eds.), Attention and performance $I X$ (Vol. 9, pp. 187-203). Hillsdale, NJ: Erlbaum.

JONIDES, J., \& MACK, R. (1984). The cost and benefit of cost and benefit. Psychological Bulletin, 96, 24-44.

Kingstone, A., \& Klein, R. M. (1991). Combining shape and position expectancies: Hierarchical process and selective inhibition. Journal of Experimental Psychology: Human Perception \& Performance, 17, $512-519$

Kingstone, A., \& Klein, R. M. (1993). Visual offsets facilitate sac- cadic latency: Does predisengagement of visuospatial attention mediate this gap effect? Journal of Experimental Psychology: Human Perception \& Performance, 19, 1251-1265.

Ki EIN, R. M. (1980). Does oculomotor readiness mediate cognitive control of visual attention? In J. B. Long \& A. D. Baddeley (Eds.), Attention and performance VIII (Vol. 8, pp. 259-276). Hillsdale, NJ: Erlbaum.

KLEIN, R. M. (1994). Perceptual-motor expectancies interact with covert visual orienting under conditions of endogenous but not exogenous control. Canadian Journal of Experimental Psychology, 48, 167-181.

KLEIN, R. M., \& HANSEN, E. (1990). Chronometric analysis of spotlight failure in endogenous visual orienting. Journal of Experimental Psychology: Human Perception \& Performance, 16, 790-801.

KLEIN, R. [M.], \& KERR, B. (1974). Visual signal detection and the locus of foreperiod effects. Memory \& Cognition, 2, 431-435.

Klein, R. M., Kingstone, A., \& Pontefract, A. (1992). Orienting of visual attention. In K. Rayner (Ed.), Eye movements and visual cognition: Scene perception and reading (pp. 46-65). New York: SpringerVerlag.

KLeIN, R. M., SChmidT, W. C., \& MÜLLER, H. J. (1998). Disinhibition of return: Unnecessary and unlikely. Perception \& Psychophysics, 60, 862-872.

KLEIN, R. M., \& TAYLOR, T. L. (1994). Categories of cognitive inhibition, with reference to attention. In D. Dagenbach \& T. H. Carr (Eds.), Inhibitory processes in attention, memory, and language (pp. 113150). San Diego, CA: Academic Press.

Kowler, E., ANDerson, E., Dosher, B., \& Blaser, E. (1994). The role of attention in the programming of saccades. Vision Research, 35, $1897-1916$.

Krommenhoek, K. P., VanOpstal, A. J., Gielen, C. C. A. M., \& VanGISBERGEN, J. A. M. (1993). Remapping of neural activity in the motor colliculus: A neural network study. Vision Research, 9, 1287-1298.

KWAK, H., \& EGETH, H. (1992). Consequences of allocating attention to locations and to other attributes. Perception \& Psychophysics, 51, 455-464.

LAMBERT, A. J., \& Hockey, R. (1986). Selective attention and performance with a multidimensional visual display. Journal of Experimental Psychology: Human Perception \& Performance, 12, 484-495.

LamberT, A. [J.], \& HockeY, R. (1991). Peripheral visual changes and spatial attention. Acta Psychologica, 76, 149-163.

Law, M. B., PratT, J., \& Abrams, R. A. (1995). Color-based inhibition of return. Perception \& Psychophysics, 57, 402-408.

Lupiáñez, J., Milán, E. G., Tornay, F. J., Madrid, E., \& Tudela, P. (1997). Does IOR occur in discrimination tasks? Yes, it does, but later. Perception \& Psychophysics, 59, 1241-1254.

LYON, D. R. (1990). Large and rapid improvement in form discrimination accuracy following a location precue. Acta Psychologica, 73, 69-82.

Mangun, G. R., Hansen, J. C., \& Hillyard, S. A. (1986, June). The spatial orienting of attention: Sensory facilitation or response bias. Paper presented at the Eighth International Conference on Eventrelated Potentials of the Brain, Stanford, CA.

Mangun, G. R., \& Hillyard, S. A. (1991). Modulations of sensoryevoked brain potentials indicate changes in perceptual processing during visual-spatial priming. Journal of Experimental Psychology: Human Perception \& Performance, 17, 1057-1074.

Massone, L. L. E. (1994). A neural-network system for control of eye movements: Basic mechanisms. Biological Cybernetics, 71, 293-305.

MAYLOR, E. (1985). Facilitatory and inhibitory components of orienting in visual space. In M. I. Posner \& O. S. M. Marin (Eds.), Attention and performance $X I$ (pp. 189-203). Hillsdale, NJ: Erlbaum.

MAYLOR, E., \& HOCKEY, R. (1985). Inhibitory component of externally controlled covert orienting in visual space. Journal of Experimental Psychology: Human Perception \& Performance, 11, 777-787.

MAYLOR, E., \& HoCKEY, R. (1987). Effects of repetition on the facilitatory and inhibitory components of orienting in visual space. Neuropsychologia, 25, 41-54.

MOHLER, C. W., \& WURTz, R. H. (1976). Organization of monkey superior colliculus: Intermediate layer cells discharging before eye movements. Journal of Neurophysiology, 39, 722-744. 
Mohler, C. W., \& Wurtz, R. H. (1977). Role of striate cortex and superior colliculus in visual guidance of saccadic eye movements in monkeys. Journal of Neurophysiology, 40, 74-94.

MüLLER, H. J., \& FINDLAY, J. M. (1987). Sensitivity and criterion effects in the spatial cuing of visual attention. Perception \& Psychophysics, 42, 383-399.

Müller, H. J., \& Rabbitt, P. M. A. (1989). Spatial cuing and the relation between the accuracy of "where" and "what" decisions in visual search. Quarterly Journal of Experimental Psychology, 41, 747-773.

MülLER, H. J., \& VON MühLENEN, A. (1996). Attentional tracking and inhibition of return in dynamic displays. Perception \& Psychophysics, 58, 224-249.

Munoz, D. P., \& WuRTz, R. H. (1992). Role of the rostral superior colliculus in active visual fixation and execution of express saccades. Journal of Neurophysiology, 67, 1000-1002.

MunOz, D. P., \& WURTZ, R. H. (1993a). Fixation cells in monkey superior colliculus: I. Characteristics of cell discharge. Journal of Neurophysiology, 70, 559-575.

MUNOZ, D. P., \& WURTZ, R. H. (1993b). Fixation cells in monkey superior colliculus: Il. Reversible activation and deactivation. Journal of Neurophysiology, 70, 576-589.

Nakayama, K., \& MaCKeben, M. (1989). Sustained and transient components of focal visual attention. Vision Research, 29, 1631-1647.

Pontefract, A. J., \& Klein, R. M. (1988). Assessing inhibition of return with simple and choice reaction time. Unpublished manuscript.

PoSNer, M. I. (1974). The psychobiology of attention. In M. Gazzaniga (Ed.), Handbook of psychobiology (pp. 441-480). New York: Academic Press.

PoSNER, M. I. (1980). Orienting of attention. Quarterly Journal of Experimental Psvchology, 32, 3-25.

Posner, M. I., \& COHEN, Y. (1980). Attention and the control of movements. In G. E. Stelmach \& J. Requin (Eds.), Tutorials in motor behavior (pp. 243-258). Amsterdam: North-Holland.

Posner, M. I., \& COHEN, Y. (1984). Components of visual orienting. In H. Bouma \& D. G. Bouwhuis (Eds.), Attention and performance $X$ (pp. 531-556). Hillsdale, NJ: Erlbaum.

Posner, M. I., Cohen, Y., Choate, L., Hockey, R., \& Maylor, E. (1984). Sustained concentration: Passive filtering or active orienting? In S. Kornblum \& J. Requin (Eds.), Preparatory states and processes (pp. 49-65). Hillsdale, NJ: Erlbaum.

Posner, M. I., Klein, R. M., Summers, J., \& Buggie, S. (1973). On the selection of signals. Memory \& Cognition, 1, 2-12.

Posner, M. I., Rafal, R. D., Choate, L. S., \& Vaughan. J. (1985). Inhibition of return: Neural basis and function. Cognitive Neuropsycholog1, 2, 211-228.

PossamaI, C. (1986). Relationship between inhibition and facilitation following a visual cue. Acta Psychologica, 61, 243-258.

PratT, J. (1995). Inhibition of return in a discrimination task. Psychonomic Bulletin \& Review, 2, 117-120.

Pratt, J., Kingstone, A., \& Khoe, W. (1997). Inhibition of return in location- and identity-based choice decision tasks. Perception \& Psychophvsics, 59, 964-971.

Rafal, R. D., Cal abresi, P. A., Brennan, C. W., \& Sciolto, T. K (1989). Saccade preparation inhibits reorienting to recently attended locations. Journal of Experimental Psychology: Human Perception \& Performance, 15, 673-685.

RAFAL, R. D., EGLY, R., \& RHODES, D. (1994). Effects of inhibition of return on voluntary and visually guided saccades. Canadian Journal of Experimental Psychology, 48, 284-300.

RafaL, R. D., \& HeNIK, A. (1994). The neurology of inhibition: Integrating controlled and automatic processes. In D. Dagenbach \& T. H. Carr (Eds.), Inhibitory processes in attention, memon; and language (pp. 1-52). San Diego, CA: Academic Press.

Rayner, K., MCCONKIE, G. W., \& Ehrlich, S. (1978). Eye movements and integrating information across fixations. Journal of Experimental Psichology: Human Perception \& Performance, 4, 529-544.

RFMINGTON, R. W. (1980). Attention and saccadic eye movements Journal of Experimental Psychologi: Human Perception \& Pertormance. 6, 726-744.

REULEN, J.P. H. (1984). Latency of visually eroked saccadic eye move- ments: I. Saccadic latency and the facilitation model. Biological $C_{y-}$ bernetics, 50, 251-262.

Reuter-Lorenz, P. A., Hughes, H. C., \& Fendrich, R. (1991). The reduction of saccadic latency by prior offset of the fixation point: An analysis of the gap effect. Perception \& Psychophysics, 49, 167-175.

Reuter-Lorenz, P. A., JHA, A. P., \& Rosenquist, J. N. (1996). What is inhibited in inhibition of return? Journal of Experimental Psychology: Human Perception \& Performance, 22, 367-378.

Rizzolatti, G., Riggio, L.. Dascola, I., \& Umiltà, C. (1987). Reorienting of attention across the horizontal and vertical meridians: Evidence in favor of a premotor theory of attention. Neuropsychologia, 25. $31-40$

SasLow, M. G. (1967). Effects of components of displacement-step stimuli upon latency for saccadic eye movement. Journal of the Optical Society of America, 57, 1024-1029.

SCHALL, J. D. (1997). Visuomotor areas of the frontal lobe. In K. S. Rockland, A. Peters, \& J. Kaas (Eds.), Cerebral cortex: Vol. 12. Extrastriate cortex of primates (pp. 527-638) New York: Plenum.

SCHILLER, P. H. (1977). The effect of superior colliculus ablation on saccades elicited by cortical stimulation. Brain Research, 122, 154-156.

SCHILler, P. H., SANDELL, J. H., \& Maunsell, J. H. R. (1987). The effect of frontal eye field and superior colliculus lesions on saccadic latencies in the rhesus monkey. Journal of Neurophysiology, 57, 1033-1049.

Schiller, P. H., True, S. D., \& Conway, J. L. (1980). Deficits in eye movements following frontal eye-field and superior colliculus ablations. Journal of Neurophysiology, 44, 1175-1189.

Schlag-Rey, M., SChlag, J., \& Dassonville, P. (1992). How the frontal eye field can impose a saccade goal on superior colliculus neurons. Journal of Neurophysiology, 67, 1003-1005.

SCHMIDT, W. C. (1996a). Inhibition of return is not detected using illusory line motion. Perception \& Psychophysics, 58, 883-898.

SChmidT, W. C. (1996b). "Inhibition of return" without visual input. Neuropsychologia, 34, 943-952

Segraves, M. A., \& PARK, K. (1993). The relationship of monkey frontal eye field activity to saccade dynamics. Journal of Neurophysiology, 69. 1880-1889.

ShePherd, M., Findlay, J. M., \& Hockey, R. J. (1986). The relationship between eye movements and spatial attention. Quarterly Journal of Experimental Psychologv, 38, 475-491.

ShiU, L., \& PASHler, H. (1994). Negligible effect of spatial precuing on identification of single digits. Journal of Experimental Psychology: Human Perception \& Performance, 20, 1037-1054.

SHIU, L., \& PASHLER, H. (1995). Spatial attention and vernier acuity, Vision Research, 35, 337-343.

SHULMAN, G. L. (1984). An asymmetry in the control of eye movements and shifts of attention. Acta Psychologica, 55, 53-69.

SPARKS, D. L. (1978). Functional properties of neurons in the monkey superior colliculus: Coupling of neuronal activity and saccade onset. Brain Research, 156, 1-16

SPARKS, D. L., \& MaYS, L. E. (1983). Spatial localization of saccade targets: I. Compensation for stimulation-induced perturbations in eye position. Journal of Neurophysiology, 49, 45-64.

Sparks, D. L., \& PorTer, J. D. (1983). Spatial localization of saccade targets: II. Activity of superior colliculus neurons preceding compensatory saccades. Journal of Neurophysiology, 49, 64-74.

SPENCE, C., \& Driver, J. (1998a). Auditory and audiovisual inhibition of return. Perception \& Psichophwsics, 60, 125-139.

SPENCE, C., \& DRIVER, J. (1998b). In hibition of return following an auditory cue: The role of central reorienting events. Manuscript submitted for publication.

Stein, B. E., \& MFrentrh, M. A. (1990). Multisensory integration: Neural and behavioral solutions for dealing with stimuli from different sensory modalities. In A. Diamond (Ed.). The development of neural bases of higher cognitive finctions (Annals of the New York Academy of Sciences, Vol. 608, pp. 51-65). New York: New York Academy of Sciences.

StelmaCh, L. B., \& Herdman, C. M. (1991). Directed attention and perception of temporal order. Joumal of Experimental Psychology: Human Perception \& Performance. 17.539-550.

STERNBFRG. S. (1969). The discovery of processing stages: Extensions 
of Donders' method. In W. G. Koster (Ed.), Attention and performance II (pp. 276-315). Amsterdam: North-Holland.

STERNBERG, S., \& KNOLL, R. L. (1973). The perception of temporal order: Fundamental issues and a general model. In S. Kornblum (Ed.), Attention and performance IV (pp. 629-685). New York: Academic Press

TANaka, T., \& Shimojo, S. (1996). Location vs feature: Reaction time reveals dissociation between two visual functions. Vision Research, 36, 2125-2140.

Tassinari, G., Aglioti, S., Chelazzi, L., Marzi, C. A., \& BerlucCHI, G. (1987). Distribution in the visual field of the costs of voluntarily allocated attention and of the inhibitory after-effects of covert orienting. Neuropsychologia, 25, 55-72.

Tassinari, G., Aglioti, S., Chelazzi, L., Peru, A., \& Berlucchi, G. (1994). Do peripheral non-informative cues induce early facilitation of target detection? Vision Research, 34, 179-189.

Tassinari, G., \& Berlucchi, G. (1993). Sensory and attentional components of slowing of manual reaction time to non-fixated visual targets by ipsilateral primes. Vision Research, 33, 1525-1534.

TASSINARI, G., \& BERLuCCHI, G. (1995). Covert orienting to noninformative cues: Reaction time studies. Behavioural Brain Research, 71, 101-112.

Tassinari, G., Biscaldi, M., Marzi, C. A., \& Berlucchi, G. (1989). Ipsilateral inhibition and contralateral facilitation of simple reaction time to nonfoveal visual targets from noninformative visual cues. Acta Psychologica, 70, 267-29l.

TASSINARI, G., \& CAMPARA, D. (1996). Consequences of covert orienting to non-informative stimuli of different modalities: A unitary mechanism? Neuropsychologia, 34, 235-245.

TAYLOR, T. L. (1997). Generating and measuring inhibition of return. Unpublished doctoral dissertation, Dalhousie University, Halifax, Nova Scotia.

TAYLOR, T. L., \& KLEIN, R. M. (1998a). Inhibition of return to color: A replication and non-extension of Law, Pratt, and Abrams (1995). Perception \& Psychophysics, 60, 1452-1456.

TAYLOR, T. L., \& KLEIN, R. M. (1998b). Motor and attentional bases of inhibition of return. Manuscript in preparation.

TerRY, K. M., VAlDES, L. A., \& NeIll, W. T. (1994). Does "inhibition of return" occur in discrimination tasks? Perception \& Psychophysics, 55, 279-286.

THEEUWES, J. (1991). Exogenous and endogenous control of attention: The effect of visual onsets and offsets. Perception \& Psychophysics, 49, 83-90.

TipPer, S. P., Driver, J., \& Weaver, B. (1991). Object-centered inhibition of return of visual attention. Quarterly Journal of Experimental Psychology, 43, 289-298.

Tipper, S. P., Weaver, B., Jerreat, L. M., \& Burak, A. L. (1994). Object-based and environment-based inhibition of return of visual attention. Journal of Experimental Psychology: Human Perception \& Performance, 20, 478-499.

VAUGHAN, J. (1984). Saccades directed at previously attended locations in space. In A. J. Gale \& C. W. Johnson (Eds.), Theoretical and applied aspects of eye movement research (pp. 143-150). Amsterdam: Elsevier

Wallace, M. T., Meredith, M. A., \& Stein, B. E. (1993). Converging influences from visual, auditory, and somatosensory cortices onto output neurons of the superior colliculus. Journal of Neurophysiology, 69, 1797-1809.

WARD, L. M. (1994). Supramodal and modality-specific mechanisms for stimulus-driven shifts of auditory and visual attention. Canadian Journal of Experimental Psychology, 48, 242-259.

WeAVER, B., LuPiáñEZ, J., \& WATSON, F. L. (1998). The effects of practice on object-based, location-based, and static-display inhibition of return. Perception \& Psychophysics, 60, 993-1003.

WERnER, W., DANNENBERG, S., \& HOFFMAN, K. P. (1997). Arm movementrelated neurons in the primate superior colliculus and underlying reticular formation: Comparison of neuronal activity with EMGs of muscles of the shoulder, arm, and trunk during reaching. Experimental Brain Research, 115, 191-205.

YANTIS, S. (1993). Stimulus-driven attentional capture and attentional control settings. Journal of Experimental Psychology: Human Perception \& Performance, 19, 676-681

YANTIS, S., \& JohNSTON, J. C. (1990). On the locus of visual selection: Evidence from focused attention tasks. Journal of Experimental Psychology: Human Perception \& Performance, 16, 135-149.

YANTIS, S., \& JONES, E. (1991). Mechanisms of attentional selection: Temporally modulated priority tags. Perception \& Psychophysics, 50, 166-178.

\section{NOTES}

1. Note that RT facilitation, as opposed to inhibition, of peripheral targets is determined by comparing cued versus uncued peripheral locations rather than by comparing these locations independently with the uncued center location. The reason for this is clear: By virtue of occurring at the location where the receptor density is greatest and where attentional resources were actively focused, foveal targets were responded to faster than the peripheral targets-regardless of the spatial relation between cue and target. That the RT effects for the peripheral targets do represent facilitation of the cued location at short SOAs and inhibition of the cued location at long SOAs is indicated by a subsequent study (Posner \& Cohen, 1984) that presented targets with equal probability at four peripheral locations to the left and the right as well as above and below fixation. At short SOAs, RTs were faster at the cued location than at any other location; at long SOAs, RTs were slowest at the cued location than at any other location.

2. Chronometric analysis of spatial cuing effects sometimes compares cued and uncued target RTs with a neutral condition in which attention is spatially dispersed. The use of a neutral cue allows for the relative parsing of RT benefits from orienting to a valid cue and RT costs from orienting to an invalid cue. However, the validity of obtained costs and benefits clearly depends on the representativeness of the neutral condition as a true baseline (see Jonides \& Mack, 1984, for cautions regarding the selection of an appropriate neutral condition).

3. Note that our operational definition of attention is based on evidence that a spatial cue in an orienting paradigm leads to enhanced perceptual processing. In other words, our definition is specific to visuospatial attention in a spatial orienting paradigm. We would also like to distinguish the effects of attentional orienting from the orienting itself. More specifically, in introducing a motor view of IOR later in the paper, we accommodate the view that attentional orienting (to an exogenous cue) may occur through oculomotor programming. However, for the purposes of considering an attentional account of IOR, a possible motor mechanism for attentional orienting is not critical: The point we are making with respect to the predictions of an attentional account of IOR is that, if IOR represents inhibited attentional orienting, perceptual processing should suffer at the cued location--regardless of the mechanisms used to orient attention. To the extent that this does not occur, the results are inconsistent with the view that IOR represents inhibited visuospatial attentional orienting to a previously cued location.

4. Biederman and Cooper (1992) have suggested that size may, in fact, be encoded in the dorsal pathway. We thank Brad Gibson for bringing this point to our attention. To the extent that coding a size change might also be coded in the dorsal pathway, Pontefract and Klein's (1988) result represents an exception to the generalization that failures to observe IOR for nonspatial target discriminations are consistent with dorsal pathway involvement.

5. In the majority of tasks failing to demonstrate IOR, a target-target paradigm was employed. The target-target paradigm presents subjects with a single onset target per trial. Subjects are required to respond on every trial, and IOR is measured as RT on trial $N$ as a function of whether the target occurred in the same versus a different location as on trial $N-1$. In such a paradigm, IOR is not observed for nonspatial target discriminations (see, e.g., Kwak \& Egeth, 1992; Tanaka \& Shimojo, 1996; Terry et al., 1994). Note that in the target-target paradigm, however, the response on trial $N$ serves as a possible mechanism for generating IOR on trial $N+1$ and also indexes any inhibition that might have been generated on trial $N-1$. As such, it is unclear whether the non- 
spatial target discrimination fails to generate IOR or whether the speed to make a nonspatial target discrimination is simply not sensitive to the effects of IOR. Alternatively, IOR may occur for nonspatial discriminations in such a paradigm, but this inhibitory process may be masked by a facilitatory effect due to target repetition.

6. This account, which works for all the studies (to date) that have observed IOR in RT using nonspatial discriminations, does have trouble with Handy et al.'s (in press) finding of IOR in $d^{\prime}$ (in addition to RT). Although such an effect has face validity for concluding that IOR affects perceptual representations (i.e., slows the rate of accumulation of information about a stimulus), a perceptual locus is not at all dictated by this finding. Klein and $\operatorname{Kerr}(1974)$, for example, in possibly the first $d^{\prime}$ study of the effects of a warning signal, argued that the effect they observed on $d^{\prime}$ was not due to a change in the quality of the accumulating evidence about the target but was instead due to the speed with which the attention/decision mechanisms consulted the rapidly decaying information from a brief and masked target. In a brief and masked target paradigm, if IOR delays the time at which information about the target is assessed for a decision, an RT delay and a decrease in sensitivity $\left(d^{\prime}\right)$ may be observed. Finally, it must be noted that this interpretation of Handy et al., although inconsistent with a perceptual locus for the effect of IOR, could be construed as consistent with an effect on attention. Indeed, that is exactly how Posner (1974; Posner, Klein, Summers, \& Buggie, 1973) interpreted the effect of alertness: Alertness influences the speed with which attention is recruited to generate a response

7. Although the arguments are made for visual stimuli, it should be noted that visual, auditory, and somatosensory output all converge on the SC (see, e.g., Stein \& Meredith,.1990; Wallace, Meredith, \& Stein, 1993), so that an SC basis of IOR does not prohibit finding the effect in other than a visual modality (e.g., Spence \& Driver, 1998a).

8. Abrams and Dobkin's (1995) use of the terms visual versus motor is not at variance with our use of the terms visuomotor and motor. The essence of their rationale is the same as that outlined in the present text. The decision to avoid their use of the word visual is based on the presented evidence that contradicts sensory-based and attention-based ef fects of IOR. Our goal is to use the term visuomotor to distinguish visual effects that may be revealed at the level of visuomotor integration from those that derive from sensory or perceptual processes.

9. In exploring the spatial coding of IOR measured by exogenous and endogenous saccades, Abrams and Dobkin (1995) revealed the possibility that the two may be dissociable. Following on the work of Tipper et al. (1991), who showed evidence of object-centered IOR, Abrams and
Dobkin (1995) examined visuomotor and motor effects in dynamic displays. They repeated the described methods, except that stimulus boxes started at locations above and below fixation and rotated clockwise through $90^{\circ}$ during the presentation of the cue at fixation. In separate experiments, the saccade command was an exogenous or an endogenous signal. Both signals required a motor response. However, in the case of an exogenous signal, the motor response was directed by a peripheral command that could appear at a potentially inhibited location, whereas in the case of an endogenous signal, the motor response was unaffected by deficits in responding on the basis of peripheral visual information. When the command was exogenous, IOR occurred for targets that appeared in the previously cued stimulus box; when the command was endogenous only, there was no evidence of object-based IOR. This dissociability of visual and motor contributions is theoretically important. However, in light of the majority of studies that have used static displays and therefore confounded space-based and object-based effects, the ability to dissociate the effects is not paramount to the present analysis.

10 . This notion that IOR may represent inhibition for responding based on information at a previously cued location has an interesting implication when considered in light of a study reported by Fuentes, Vivas, and Humphreys (in press). They presented subjects with a flanker task in which the distractor occurred in a previously cued versus uncued location. That is, subjects were presented with an exogenous cue to the periphery and then back to center. Then (on a portion of trials), a letter or number appeared at fixation, and subjects were required to make a number/letter discrimination. Presented simultaneously with this discrimination target was a letter/number at either the cued or the uncued location. Normally, a flanker that maps onto the same response as the target speeds RT, whereas a flanker that maps onto an incompatible response slows RTs to the target. For example, if subjects are presented with a target letter at fixation, they will typically be faster to respond if the flanking distractor is also a letter, as opposed to when it is a number. And, in fact, this pattern of results emerged when the flanker appeared at the uncued location. However, when the flanker appeared at the previously cued location, this flanker effect was reversed. From this finding, Fuentes et al. argued that IOR acts on the connection between activated identities and responses. It remains to be seen how this effect will be related to the motor and visuomotor effects we have outlined here for spatial IOR paradigms.

(Manuscript received October 2, 1997; revision accepted for publication March 26, 1998.) 